\title{
The characterisation of the interfacial interaction between polymeric methylene diphenyl diisocyanate and aluminium: A ToF-SIMS and XPS study
}

\author{
Kyoko Shimizu $^{1 *}$, Christopher Phanopoulos ${ }^{2}$, Marie-Laure Abel ${ }^{1}$ and John F. Watts ${ }^{1}$ \\ ${ }^{1}$ Surrey Materials Institute and Faculty of Engineering \& Physical Sciences, \\ University of Surrey, Guildford, Surrey, GU2 7XH, UK \\ ${ }^{2}$ Huntsman PU, Everslaan, Everberg, 3078 Belgium \\ *E-mail address: k.shimizu@ surrey.ac.uk
}

\begin{abstract}
Time of flight secondary ion mass spectrometry (ToF-SIMS) and X-ray photoelectron spectroscopy (XPS) have been employed to study the interfacial interaction between polymeric methylene diphenyl diisocyanate (PMDI) and aluminium produced by the deposition of a thin PMDI layer on the aluminium, in order to improve adhesion and/or abhesion performance.

When the PMDI concentration increases, the intensity ratio fragments indicative of the reaction product with water $\left(\mathrm{m} / \mathrm{z}=106 \mathrm{u}: \mathrm{C}_{7} \mathrm{H}_{8} \mathrm{~N}^{+}\right)$to that of isocyanate group $(\mathrm{m} / \mathrm{z}=132 \mathrm{u}$ : $\mathrm{C}_{8} \mathrm{H}_{6} \mathrm{NO}^{+}$) decreases. A very thin MDI layer on oxidised aluminium samples exhibits lower 106/132 ratio than degreased samples as a result of less hydroxide/hydroxyl spices on the surface. This suggests that water reactions occur both at the surface of PMDI and at the PMDI/aluminium interface. The variation of the PMDI chemistry has also been studied by exposing PMDI treated samples to the air for various periods of time (a few hours to 14 days), in order to assess the reaction of the PMDI surface and PMDI/aluminium interface. At the interface, the yield of reaction with water is limited because of the finite amount of hydroxyl groups on the aluminium surface, and the water reaction is completed in a short period of time. However, the PMDI surface continues to react with water from the atmospheric. This methodology was also used to establish the presence of specific interactions at the PMDI/aluminium interface, and a fragment indicative of covalent bond formation between PMDI and aluminium $\left(\mathrm{AlCHNO}_{3}{ }^{-}\right)$is observed at the interface.
\end{abstract}


Keywords: Isocyanate, polyurethane, aluminium, interface interaction, ToF-SIMS, XPS

\section{Introduction}

Polyurethane (PU) contains the urethane linkage (-NHCOO-) in its backbone chain, formed by the reaction of an isocyanate with a polyol in the presence of catalysts and other additives. PUs exist in numerous forms ranging from flexible or rigid lightweight foams to tough, stiff elastomers [1]. MDI based polyurethanes are used in a wide range of applications: automotive, footwear, construction, furniture, thermal insulation, packaging industry, adhesives and coatings [1]. In this work, the interface interaction between PMDI and aluminium has been studied usin ToF-SIMS and XPS, in order to develop release options from aluminium moulds during manufacture process and/or improve the adhesive performance for aluminium substrates.

The isocyanate group of PMDI reacts with compounds that contain active hydrogen groups such as hydroxyl, water, amine, urea and urethane, but also with other isocyanates. In the reaction with water, carbamic acid is produced, and the carbamic acid breaks down into amine and carbon dioxide. The amine then reacts with another isocyanate to form substituted urea, as show in Figure 1a. The reaction of an isocyanate group with a hydroxyl group of polyol forms a urethane linkage (Figure 1b). The isocyanate also reacts with urea to form biuret via active hydrogen (Figure 1c), while the reaction with urethane forms allophanate (Figure 1d). The isocyanates can react with themselves to form uretdione (dimer) (Figure 1e) and isocyanurate (trimer) (Figure 1f). The isocyanate also produces carbodiimide and carbon dioxide by reacting with themselves and the carbodiimide slowly reacts with another isocyanate to form uretonimine (Figure $1 \mathrm{~g}$ ). The high reactivity of isocyanate groups with active hydrogen is potentially the most important aspect of the interaction between isocyanates and metals. There are several assumptions in the mechanism of interaction between an isocyanate group and a metal surface [2-4]. Dillingham et al. have studied the interface interaction between isocyanate based polymer and steel using Fourier transform infrared reflection (FT-IR) and the mechanism proposed is that the isocyanate functional groups can react with hydrated oxide on the metal surface to form carboxylate salts as shown below [2]:

$$
-\mathrm{N}=\mathrm{C}=\mathrm{O}+\mathrm{M}-\mathrm{OH} \cdot \mathrm{H}_{2} \mathrm{O} \rightarrow-\mathrm{NH}-\mathrm{COOH}+\mathrm{M}-\mathrm{OH} \rightarrow-\mathrm{NH}-\mathrm{COO}^{-}+\mathrm{M}-\mathrm{OH}_{2}{ }^{+}<1>
$$


where $\mathrm{M}$ is a metal. Subsequently, the carboxylate salts form covalent metal oxide-urethane linkages at higher temperature. Chehimi et al. have studied the interfacial reaction between aromatic moisture-cured urethane (ArMCU) and steel using XPS [3]. They investigated the change in the oxide state of iron when ArMCU is deposited on the steel and suggested that covalent bonds are formed at the interface via hydroxyl groups from the steel surface, with a concomitant reduction of the oxidation state of iron. Kim et al. have studied an interface reaction between a phenyl isocyanate and an aluminium hydroxide surface using electrochemical tests and optical observation. They have deduced a reaction mechanism using molecular modelling [4]. Both the electrochemical test and optical observation imply that the isocyanate functional group prefers to react with hydroxide aluminium. The charge distribution map of phenyl isocyanate, the negative charge on the nitrogen and oxygen and the positive charge on the carbon of the icocyanate group, suggests that the nitrogen and carbon atoms of phenyl isocyanate favourably interacts with hydrogen and oxygen atoms of hydroxide groups on aluminium surface, and this results in the formation of covalent bond via urethane linkage.

In this work, ToF-SIMS and XPS have been employed to study the interaction of PMDI with aluminium. ToF-SIMS can obtain the elemental and chemical information of the outermost molecular or atomic layer of a solid surface and the sensitivity is extremely high for all elements. XPS is utilised to determine all elements apart from $\mathrm{H}$ and $\mathrm{He}$, and their chemical bonds. The information is obtained from the first few atomic layers and the detection limit is about 0.1 at. \%. The combination of ToF-SIMS and XPS analysis techniques are particularly powerful for the comprehensive definition of polymer surface chemistry and the interaction of organic molecules with solid substrates. The aim of this work is to improve the knowledge of possible isocyanate-aluminium interactions. To this end the interface interaction between PMDI and aluminium produced by deposition of a thin layer of PMDI on three different pretreated aluminium substrates has been studied. In order to assess the reaction of PMDI surface with atmospheric moisture and interface reaction between PMDI and aluminium, the variation of chemistry of PMDI on degreased aluminium has been examined by exposing the samples to ambient atmosphere for various periods of time.

\section{Experimental}

\subsection{Sample preparation}


Aluminium sheets (99.9 \% purity) were supplied by Chronos Ltd (Bedfordshire, UK). Samples of $10 \times 10 \mathrm{~mm}^{2}$ were cut from $0.9 \mathrm{~mm}$ thick aluminium sheets and subsequently cleaned with acetone using an ultrasonic bath to remove any organic contaminants. Then three different pretreated aluminium substrates, which are degreased, oxidised and hydrolysed aluminium, were prepared with varied surface hydroxyl concentrations. The oxidised aluminium were made by heating in an oven at $220^{\circ} \mathrm{C}$ for 2 hours and then stored in a desiccator, while the aluminium were hydrolysed by placing in a boiling deionised water for an hour.

MDI (Suprasec 5025, Huntsman Holland BV, Rotterdam, The Netherlands) solution in the range of 10 to 0.01 vol. $\%$ in acetone were prepared to produce different thicknesses of MDI adhesive layers on these different pretreated aluminium substrates. The MDI solutions were deposited on these aluminium substrates by spin coating. Duplicate samples were prepared for ToF-SIMS and XPS analysis at each concentration. The samples were left in ambient atmosphere (at room temperature and relative humidity are between 55 and $85 \%$ ), for various periods of time (a few hours to 14 days) in order to assess the reaction of the MDI surface with moisture from atmosphere, in comparison to the reaction at the interface between MDI and aluminium.

Standard samples of high concentration of urea, urethane, uretdione and isocyanurate were prepared by Huntsman PU, and compositions and structures of these samples are shown in Table 1. High urethane and high isocyanurate samples were cut to expose fresh inside surfaces. High urea and high uretdione samples were supplied in powder form. The high urea samples were compressed to pellets, while the high uretdione samples were prepared for analysis by placing the powder on an aluminium coupon. Undiluted MDI was also examined by ToF-SIMS.

\subsection{XPS analysis}

XPS analysis was achieved using a modified ESCALAB MKII spectrometer (THERMO FISHER SCIENTIFIC, East Grinstead, UK). The electron energy analyser of the ESCALAB was updated to a Thermo Alpha 110. The analyser was operated in the constant analyser energy (CAE) mode at a pass energy of $100 \mathrm{eV}$ for the survey spectra and a pass energy of 20 $\mathrm{eV}$ for high resolution spectra of the elements of interest. A non-monochromated $\mathrm{Al} \mathrm{K \alpha}$ 
radiation with an energy $1486.6 \mathrm{eV}$ at power of $300 \mathrm{~W}$ was used. The analysis area was ca. 6 $\mathrm{mm}$ in diameter. A binding energy (BE) of $285.0 \mathrm{eV}$ for the $\mathrm{C}-\mathrm{C} / \mathrm{C}-\mathrm{H}$ components of $\mathrm{C} 1 \mathrm{~s}$ peak has been used as reference for charge correction. Spectral processing was carried out using the manufacture's software Avantage (v.4.37). The surface compositions are obtained from the high resolution spectra using sensitivity factors supplied with Avantage.

\subsection{ToF-SIMS analysis}

ToF-SIMS analysis was achieved using a TOF.SIMS 5 (ION-TOF GmbH, Münster, Germany). Static SIMS conditions with a total ion dose less than $1 \times 10^{13}{\text { ions } \mathrm{cm}^{-2} \text { analysis }}^{-1}$ were employed using a $9.5 \mathrm{eV} \mathrm{Bi}_{3}{ }^{+}$primary ion beam operating in the high current bunched mode for high spectral resolution [5]. An analysis area of $100 \times 100 \mu \mathrm{m}^{2}$ at a resolution of 64 x 64 pixels was used. ToF-SIMS spectra were acquired over a mass range of 1-850 u in both positive and negative ion modes. Charge compensation was achieved using a pulsed electron flood source. Fragments of known composition, such as $\mathrm{H}^{+}, \mathrm{CH}_{3}{ }^{+}, \mathrm{Na}^{+}, \mathrm{H}^{-}, \mathrm{C}^{-}, \mathrm{O}^{-}$and $\mathrm{OH}^{-}$ were used for mass calibration and carefully checked these peak shapes did not have any charging effect. In addition, characteristic aluminium and PMDI fragments were also used.

The ToF-SIMS intensities for particular fragment ions under consideration are evaluated using the concept of their relative peak intensity (RPI), which is the ratio of the intensity of the ion of interest relative to the total ion intensity from $\mathrm{m} / \mathrm{z}=0$ to $850 \mathrm{u}$ [6]:

$$
\mathrm{RPI}_{\mathrm{x}}=\mathrm{I}_{\mathrm{x}} / \mathrm{I}_{\text {total }} \quad<2>
$$

where $\mathrm{x}$ is the ion of interest and $\mathrm{I}_{\text {total }}$ is the total ion intensity between $\mathrm{m} / \mathrm{z}=1$ and $840 \mathrm{u}$, and $\mathrm{I}_{\mathrm{X}}$ is the measured intensity of the ion under consideration.

Peak-fitting of the high resolution ToF-SIMS spectra of nominal mass 102 was carried out using the computer software CasaXPS (v.2.3.16) provided by Casa Software Ltd. (Teignmouth, UK) [7-8]. The line shape used was a numerical convolution of a Lorentzian with a Gaussian, and the asymmetry index (a) is given by:

$$
\mathrm{a}=1-\left(\mathrm{HWHM}_{\text {right }} / \mathrm{HWHM}_{\text {left }}\right) \quad<3>
$$

where $\mathrm{HWHM}_{\text {right }}$ and $\mathrm{HWHM}_{\text {left }}$ are the half width at half maximum of the right and left asymmetric side of peak, respectively.

The accuracy of mass assignment, $\Delta$ (in ppm), is given by [9-10]:

$$
\Delta=\left|\mathrm{M}_{\text {mea }}-\mathrm{M}_{\mathrm{ex}}\right| / \mathrm{M}_{\mathrm{ex}} \quad<4>
$$


where $M_{\text {mea }}$ is the measured mass obtained from high resolution spectrum and $M_{e x}$ is the exact mass of the molecules.

\section{Results and discussion}

\subsection{XPS analysis}

\subsubsection{Aluminium surface after pretreatments}

The surface compositions of three different pretreated aluminium surfaces are shown in Table 2. Degreased aluminium exhibits a relatively high carbon concentration with a low concentration of aluminium and oxygen, compared with oxidised and hydrolysed samples. The carbon signal has decreased while aluminium and oxygen signals are increased both after oxidation and hydration. The carbon originates mainly from hydrocarbon, but also oxygen and hydroxyl functionalized carbon are observed. Four components, C-C/C-H $(\mathrm{BE}=285.0$ $\mathrm{eV}), \mathrm{C}-\mathrm{O} / \mathrm{C}-\mathrm{OH},(\mathrm{BE}=286.3-286.4 \mathrm{eV}), \mathrm{C}=\mathrm{O}(\mathrm{BE}=287.8-287.9 \mathrm{eV})$ and $\mathrm{O}-\mathrm{C}=\mathrm{O}(\mathrm{BE}=$ 288.8-289.5 eV), were used in the C1s peak fits, as shown in Figure 2 and Table 3 [11]. The adventitious hydrocarbon is evaporated upon heating. By contrast, the adventitious carbon is desorbed from aluminium surface to the boiling deionised water. When the aluminium substrate is taken out from the boiling deionised water, the aluminium surface has high surface free energy and hence the adventitious hydrocarbon is adsorbed on the surface. By hydration, the aluminium surface becomes a porous as a result of a formation of pseudoboehmite [6, 12-13], and hence more surface area leads to the reduction of the adventitious carbon concentration compared with the degreased substrate. Since $\mathrm{O}=\mathrm{C}(\mathrm{BE}=$ 532.0-532.1 eV) and $\mathrm{O}-\mathrm{C}(\mathrm{BE}=533.2-533.6 \mathrm{eV})$ components can also be observed in the $\mathrm{O} 1 \mathrm{~s}$ peaks, the cross reference of $\mathrm{C} 1 \mathrm{~s}$ and $\mathrm{O} 1 \mathrm{~s}$ peak fits allow to quantify aluminium oxide $\left(\mathrm{O}^{2-}\right)$ and hydroxide $\left(\mathrm{OH}^{-}\right)$components of $\mathrm{O} 1 \mathrm{~s}$. C-C/C-H peak at $285.0 \mathrm{eV}$ has been used as reference for charge correction, however, this correction is not appropriate to use for aluminium oxide/hydroxide because there is a vertical differential charge between adventitious carbon layer and aluminium oxide/hydroxide surface, and hence a shift in the aluminium oxide/hydroxide of A12p and O1s peaks are independent from the C1s peak [1416]. In order to determine the position of $\mathrm{O}^{2-}, \mathrm{OH}^{-}$and $\mathrm{H}_{2} \mathrm{O}$, the separations between these components of $\mathrm{O} 1 \mathrm{~s}$ and the $\mathrm{Al}^{3+}$ of $\mathrm{Al} 2 \mathrm{p}$ peaks are calculated to be 456.5-456.6 eV, 457.2- 
$457.9 \mathrm{eV}$ and $460.3 \mathrm{eV}$, respectively [14-15]. The O1s peak fit shows that the hydroxide aluminium surface has the highest amount of hydroxide groups on the surface, while surface of oxidised aluminium has the lowest hydroxide concentration, as shown in Figure 3 and Table 4. The Al2p peak fits reveal only $\mathrm{Al}^{3+}$ for the hydrolysed aluminium, whereas both $\mathrm{Al}^{0}$ and $\mathrm{Al}^{3+}$ are present in the degreased and the oxidised aluminium substrates, as shown in Figure 4 and Table 5. A thick pseudoboehmite (AlOOH) layer is formed by hydration [1215] and the pseudoboehmite layer is much thicker than oxy/hydroxyl layer of degreased and oxidised aluminium. The degreased and the oxidised aluminium substrates exhibit similar $\mathrm{Al}^{3+} /\left(\mathrm{Al}^{0}+\mathrm{Al}^{3+}\right)$ ratios, 0.86 and 0.81 respectively. However, the oxidised aluminium exhibits thinner carbonaceous layer on the surface than the degreased aluminium, and hence the detection of aluminium signal is deeper than the degreased sample. In this case, the oxide layer of oxidised aluminium is assumed to be thicker than that of degreased aluminium.

\subsubsection{MDI deposited on aluminium substrate}

XPS analysis has been employed to estimate the variation of the PMDI layer thickness on aluminium substrates, and to examine at which concentration the interface between PMDI and aluminium substrates can be examined. Table 6 shows the surface composition of the degreased aluminium and PMDI treated aluminium samples. The degreased aluminium sample exhibits a slightly higher carbon concentration together with a lower concentration of oxygen and aluminium than the sample treated with 0.01 vol. \% PMDI. This is probably a result of the displacement of adventitious carbon by a spin cast PMDI coating. When the PMDI concentration increases, intensities of carbon and nitrogen increase while the intensity of aluminium decreases.

Table 7 shows the surface concentrations for the different chemical states of carbon established by peak fitting of the $\mathrm{C} 1 \mathrm{~s}$ core level spectra. The first $\mathrm{C} 1 \mathrm{~s}$ peak at $\mathrm{BE} 285.0 \mathrm{eV}$ is assigned to hydrocarbon, C-C/C-H. The BE of the second peak between 285.8 and $286.7 \mathrm{eV}$ is assigned to alcohol and/or ether carbon groups, $\mathrm{C}-\mathrm{O} / \mathrm{C}-\mathrm{OH}$, and $\mathrm{C}-\mathrm{N}$, the $\mathrm{BE}$ of the third peak ranges between 287.8 and $288.3 \mathrm{eV}$ is assigned to carbonyl carbon, $\mathrm{C}=\mathrm{O}$, the $\mathrm{BE}$ of forth peak between 289.1 and $289.4 \mathrm{eV}$ is assigned to acid and ester carbon groups, $\mathrm{O}-\mathrm{C}=\mathrm{O}$, and $\mathrm{N}=\mathrm{C}=\mathrm{O}, \mathrm{N}-\mathrm{CN}=\mathrm{O}$ and $\mathrm{N}-\mathrm{COH}=\mathrm{O}[3,11,17]$. The last peak present at high $\mathrm{BE}$ between 291.4 and $291.7 \mathrm{eV}$ is due to a shake-up satellite resulting from the $\pi \rightarrow \pi^{*}$ transition in the phenyl ring [Error! Reference source not found., 18]. As the concentration of MDI increases, all peak signals increase apart from $\mathrm{C}=\mathrm{O}$ bonding. The $\mathrm{BE}$ of $\mathrm{N}=\mathrm{C}=\mathrm{O}, \mathrm{N}-\mathrm{CN}=\mathrm{O}$ 
and $\mathrm{N}-\mathrm{CO}=\mathrm{O}$ components are similar with each other so these components cannot be distinguished from peak position. Theoretically, MDI has same ratio of $\mathrm{C}-\mathrm{N}$ to $\mathrm{N}=\mathrm{C}=\mathrm{O}$, while the ratio of $\mathrm{C}-\mathrm{N}$ to $\mathrm{N}-\mathrm{CN}=\mathrm{O}$ increases as a result of formation of carbon dioxide. In this experiment, however, $\mathrm{O}-\mathrm{C}=\mathrm{O}$ component of adventitious carbon is greatly contributed as PMDI concentration decreases. Therefore, it is difficult to examine the interface reaction from $\mathrm{C} 1 \mathrm{~s}$ peak fitting.

Thickness of the carbonaceous layer can be calculated using the modified Beer-Lambert equation [18-19]:

$$
\mathrm{d}=\lambda_{\mathrm{c}} \cos \theta \ln \left(1+\mathrm{D}_{\mathrm{Al}} \lambda_{\mathrm{Al}} \mathrm{I}_{\mathrm{c}} / \mathrm{D}_{\mathrm{c}} \lambda_{\mathrm{c}} \mathrm{I}_{\mathrm{Al}}\right) \quad<5>
$$

where $d$ is the carbonaceous thickness, $D_{A l}$ and $D_{c}$ are the densities of the aluminium and carbon, $\lambda_{\mathrm{Al}}$ and $\lambda_{\mathrm{c}}$ are the attenuation length of the photoelectrons in the aluminium and in the carbon, $I_{A l}$ and $I_{c}$ are the intensities of the aluminium and the carbon, and $\theta$ is the photoelectron take-off angle to the surface normal (set at $\theta=45^{\circ}$ for these experiments). Densities of PMDI and aluminium are 1.23 and $2.7 \mathrm{~g} \mathrm{~cm}^{-3}$, respectively [20-21]. The attenuation lengths of $\mathrm{C} 1 \mathrm{~s}$ and $\mathrm{Al} 2 \mathrm{p}$ are 2.4 and $2.8 \mathrm{~nm}$, respectively $[19,22]$. The carbonaceous thicknesses of PMDI treated degreased aluminium samples are in a range of 2.8 to $7.5 \mathrm{~nm}$ as shown in Table 8 . These thicknesses are appropriate to examine from the reaction of PMDI surface to the interface interaction between PMDI and aluminium using ToF-SIMS. 0.05 and 0.25 vol. \% MDI treated hydrolysed aluminium samples has less carbonaceous layer than degreased and oxidised samples. By hydration, the porous surface is formed, and thus the increase in surface area leads to the reduction of the carbonaceous layer thickness.

\subsection{ToF-SIMS analysis}

\subsubsection{Reference samples}

There are several reaction products of isocyanate as mentioned in the introduction. The most important reactions are with water, with hydroxyl groups and NCO/NCO reactions under a range of conditions and in the presence of different types of catalysts. Therefore, some of these possible reaction products are examined by ToF-SIMS in order to have references for 
the interpretation of the ToF-SIMS data relative to interface interaction between PMDI and aluminium. Figure 5 shows the positive ToF-SIMS spectra in the mass range of $\mathrm{m} / \mathrm{z}=1-300$ $\mathrm{u}$ of the reference samples. From PMDI sample, at lower mass region, high intensities of $\mathrm{Na}^{+}$, $\mathrm{CH}_{3} \mathrm{O}^{+}, \mathrm{C}_{3} \mathrm{H}_{5}^{+}, \mathrm{C}_{2} \mathrm{H}_{3} \mathrm{O}^{+}, \mathrm{C}_{2} \mathrm{H}_{5} \mathrm{O}^{+}, \mathrm{C}_{3} \mathrm{H}_{7} \mathrm{O}^{+}, \mathrm{C}_{6} \mathrm{H}_{5}{ }^{+}$and $\mathrm{C}_{4} \mathrm{H}_{7} \mathrm{O}^{+}$are observed and these are either MDI derived fragments, and/or fragments of materials present in the PMDI production process. High intensities of fragments of isocyanate functional groups $(\mathrm{m} / \mathrm{z}=132,206,249$ and $263 \mathrm{u}$ ) are observed in the PMDI sample. Low intensity of a fragment of an amine functional group $(\mathrm{m} / \mathrm{z}=106 \mathrm{u})$ is also observed, and this fragment probably originates from the reaction product of PMDI exposed to atmospheric moisture before the analysis so that there is a small yield of the water reaction product on the PMDI surface. A typical PMDI contains a mixture of di-iso (30-50 wt. \%), tri-iso (20-30 wt. \%) and small amounts of tetra, penta isocyanates and higher homologue $[1,23]$. The tri-isocynate component of PMDI is used to show possible PMDI origin fragments as shown in Figure 6 [24]. Only one of the possible fragments at each mass is presented since there might be different charge localisation and structures.

Table 9 suggests possible ion assignments for positive ion fragments originating from MDI as well as from its common reaction products [25-26]. Both the amine group $(\mathrm{m} / \mathrm{z}=106$ $\mathrm{u})$ and the isocyanate group $(\mathrm{m} / \mathrm{z}=132 \mathrm{u})$ are observed in all reference samples. The relative ratios of mass $106 \mathrm{u}$ to $132 \mathrm{u}$ in the PMDI, high uretdione, high isocyanurate, high urethane and high urea samples are $0.1,0.4,0.5,1.0$, and 2.8, respectively. This high 106/132 ratio of high urethane and urea can use as an indication of the formation of reaction products with hydroxyl groups and water for PMDI treated aluminium samples.

For the high urea and urethane samples, peaks of isocyanate groups $(\mathrm{m} / \mathrm{z}=132 \mathrm{u})$, amine groups $(\mathrm{m} / \mathrm{z}=106,195$ and $197 \mathrm{u})$ and both amine and isocyanate groups $(\mathrm{m} / \mathrm{z}=223$ u) are observed. However, the relative intensities are different, for example, the ratio of fragments at mass 195 to $197 \mathrm{u}$ for high urea and urethane samples are 0.4 and 1.6, respectively. A peak of high intensity, which has both isocyanate and amine functional groups $(\mathrm{m} / \mathrm{z}=223 \mathrm{u})$, and that of relatively low intensity, which has two amine groups $(\mathrm{m} / \mathrm{z}=$ $197 \mathrm{u}$ ), are observed from the high uretdione sample. The intensity of the peak at mass $263 \mathrm{u}$ is low compared with that of the PMDI sample while that of the peaks at mass 106 and $223 \mathrm{u}$ are high. For the high isocyanurate sample, fragments of isocyanurate groups $(\mathrm{m} / \mathrm{z}=132$ and $206 \mathrm{u})$ and of amine groups $(\mathrm{m} / \mathrm{z}=106 \mathrm{u})$ are observed. Table 10 shows the summary of the main characteristic fragments observed from the reference samples. Overall, the PMDI and the high uretdione samples have fragments that contain many isocyanate groups whereas the 
high urea and urethane samples exhibited more amine groups, as may have been expected since the PMDI and high uretdione materials are essentially unreacted NCO bearing materials, whilst the high urea and urethane products are formed by consuming the NCO groups by reaction with alcohols and water respectively.

\subsubsection{MDI deposited on aluminium substrate}

Figure 7 shows the positive ToF-SIMS spectra for different PMDI concentrations coated on degreased aluminium substrates in the mass range of $100-140$ and $180-290 \mathrm{u}$. MDI treated aluminium samples were stored under vacuum of the ToF-SIMS introduction chamber within a few hours of preparation, in order to prevent a further reaction with atmospheric moisture. From 5 vol. \% PMDI treated aluminium sample, high intensities of fragments containing isocyanate functional groups $(\mathrm{m} / \mathrm{z}=132,206,249$ and $263 \mathrm{u})$, originating from PMDI, are observed. When PMDI concentration decreases, intensities of these fragments decrease while intensities of fragments $(\mathrm{m} / \mathrm{z}=106,195,197$ and $223 \mathrm{u})$, originating from the reaction product of isocyanate with water, increase. Figure 8 shows a schematic of the depth information of PMDI treated aluminium samples. A fragment originating from PMDI is observed on the PMDI surface and bulk. As PMDI thickness decreases, the fragment will be detected from only the PMDI layer. The surface of PMDI can react with water from atmospheric moisture and the water reaction also occurs at the interface between PMDI and aluminium via hydroxide groups on the aluminium surface [27-28]. Therefore, a fragment which originates from water reaction is observed at the surface of PMDI and at the interface between PMDI and aluminium. For thick PMDI coated samples, 10 and 5 vol. \% PMDI treated samples have more than $7.5 \mathrm{~nm}$ thickness of the carbonaceous layer on the surface and $\mathrm{Al}^{+}$fragments $(\mathrm{m} / \mathrm{z}=27 \mathrm{u})$ are not observed from the spectra. The film is too thick to observe the interface, and hence the all fragments are observed only from the PMDI surface and bulk. By contrast, $\mathrm{Al}^{+}$fragments are observed on less than 1 vol. \% PMDI concentration samples and the intensity of $\mathrm{Al}^{+}$peak increases with reducing PMDI thickness. Therefore, the signals are observed from both the PMDI and the interface between PMDI and aluminium, and for very thin layer PMDI sample the signals are observed at the interface region, and are mainly reaction products both from hydroxide groups on the aluminium surface and from atmospheric moisture.

PMDI deposited in the oxidised and hydrolysed aluminium substrates have examined to study the interface reaction in order to compare with PMDI treated degreased aluminium 
samples. Figure 9 shows the ratio of the fragment at mass $106 \mathrm{u}$ and $132 \mathrm{u}$ of three different types of aluminium treated with variable PMDI concentration. 5 vo. \% MDI treated degreased and oxidised samples exhibit similar 106/132 ratio, while the ratio is high on 5 vol. \% treated hydroxide sample, and this is because on 5 vol. \% treated hydroxide sample has more surface area to react with atomospheric moisuture than 5 vo. \% MDI treated degreased and oxidised samples. For 0.25 and 0.05 vol. \% samples, the 106/132 ratios of oxidised aluminium are lower than degreased samples. The carbonaceous thicknesses of oxidised samples are similar, or even thinner, than degreased samples so that the amount of reaction products from atmospheric moisture are similar with both samples, therefore, the differences can be the amount of reaction products with hydroxide groups in the aluminium surface, as a result of less hydroxide on the surface of oxidised aluminium substrate than degreased substrate. By contrast, the 106/132 ratios of hydrolysed samples are high compared with degreased samples. This is because PMDI layers are thinner than degreased aluminium as a result of the formation of porous surface by hydration, and also more reaction product with hydroxide groups might be produced due to higher concentration of hydroxide groups on the surface than degreased aluminium surface.

PMDI treated aluminium samples are exposed to air for various periods in order to assess the reaction of PMDI surface and interface between PMDI and aluminium. Figure 10 shows the 106/132 ratios as a function of concentration at different times. When the PMDI concentration decreases, the ratio increases as a result of the dominance of the ion indication of reaction in interface region. As the samples are exposed to atmosphere, the ratio generally increases. For the lower PMDI concentration samples, however, the 106/132 ratio does not change significantly compared with the higher PMDI concentration samples. The PMDI reacts with atmospheric moisture on the surface of PMDI layer and the water supply is unlimited, therefore, the PMDI still proceeds to react with water by exposing the samples to air. By contrast, at the interface region, there is a finite amount of hydroxide groups on the aluminium surface so that the water reaction stops after the PMDI has depleted the available hydroxyl groups, and the water reaction at the interface is completed in a short period of time, at least within a few hours.

\subsubsection{Specific interaction between MDI and aluminium}


Figure 11 shows the high resolution spectra at mass $102 \mathrm{u}$ for degreased aluminium treated with PMDI at different concentrations, and Table 11 presents the fragments obtained at nominal mass $102 \mathrm{u}$ and their respective assignments. Peak-fitting helps identify a weak peak and/or two peaks close to each other. In this case, peak signals of $\mathrm{Al}_{2} \mathrm{O}_{3}{ }^{-}$and $\mathrm{AlCHNO}_{3}{ }^{-}$for high concentration PMDI treated samples (more than 0.25 vol. \%) are small and hence the presence of the peaks and the peak positions become clear by peak-fitting. Additionally, fragments of $\mathrm{C}_{2} \mathrm{O}_{2} \mathrm{Na}_{2}{ }^{-}$on degreased aluminium can be identified by knowing the peak position.

The XPS data indicates a $4.1 \mathrm{~nm}$ carbonaceous layer on the 0.05 vol. \% PMDI coated aluminium sample. This PMDI layer is thin enough to observe the interface. ToF-SIMS analysis of this interface reveals a mass of 102, which is composed of three components. The lowest mass fragment can be assigned to $\mathrm{Al}_{2} \mathrm{O}_{3}{ }^{-}$which originates from the aluminium substrate [29]. The highest mass fragment can be assigned to $\mathrm{C}_{7} \mathrm{H}_{4} \mathrm{~N}^{-}$which originates from the PMDI adhesive. The intermediate mass fragment is assigned to $\mathrm{AlCHNO}_{3}{ }^{-}$which indicates a covalent bond formation between aluminium and PMDI, and the proposed structure of the $\mathrm{AlCHNO}_{3}{ }^{-}$fragment is shown in Figure 12. When the thickness of the PMDI layer increases, the intensities of the $\mathrm{AlCHNO}_{3}{ }^{-}$and $\mathrm{Al}_{2} \mathrm{O}_{3}{ }^{-}$fragments decrease while the intensity of the $\mathrm{C}_{7} \mathrm{H}_{4} \mathrm{~N}^{-}$fragment increases. On the degreased aluminium sample, the $\mathrm{Al}_{2} \mathrm{O}_{3}{ }^{-}$ fragment is observed. A second higher mass fragment is also observed on the neat substrate surface which can be assigned to $\mathrm{C}_{2} \mathrm{O}_{2} \mathrm{Na}_{2}^{-}$. This is a result of the presence of $\mathrm{Na}_{2} \mathrm{O}^{-}, \mathrm{Na}_{2} \mathrm{O}_{2}^{-}$, $\mathrm{Na}_{2}{ }^{+}$and $\mathrm{Na}_{2} \mathrm{OH}^{+}$. The distance between $\mathrm{AlCHNO}_{3}{ }^{-}$fragment of MDI treased samples and $\mathrm{C}_{2} \mathrm{O}_{2} \mathrm{Na}_{2}{ }^{-}$fragment of degreased aluminium is between 7.5 and $11.0 \mathrm{mu}$, and this is enough to distinguish each fragment. Besides, MDI treated samples exhibit much low intensities of $\mathrm{Na}_{2} \mathrm{O}^{-}, \mathrm{Na}_{2} \mathrm{O}_{2}^{-}, \mathrm{Na}_{2}{ }^{+}$and $\mathrm{Na}_{2} \mathrm{OH}^{+}$compared with degreased aluminium sample, therefore, $\mathrm{C}_{2} \mathrm{O}_{2} \mathrm{Na}_{2}{ }^{-}$fragment can be negligible for MDI treated samples. Thus it can be concluded that a fragment assignable to $\mathrm{AlCHNO}_{3}{ }^{-}$is present at the interface between PMDI and aluminium, and is characteristic of a specific reaction between the isocyanate and the aluminium substrate.

\section{Conclusions}

A study of interface interaction of PMDI and aluminium has been carried out using XPS and ToF-SIMS. The following conclusions can be drawn from the work described in this paper: 
- Water reaction occurs both at the surface of PMDI and at the interface between PMDI and aluminium.

- At the interface, there is a limit on the yield of reaction with water because of the finite amount of hydroxyl groups and adsorbed water on the metal surface, and the water reaction is completed within a short period of time. By contrast, the PMDI surface continues to react with water from atmospheric moisture.

- A fragment indicative of covalent bond formation between PMDI and aluminium $\left(\mathrm{AlCHNO}_{3}{ }^{-}\right)$was observed at the interface between PMDI adhesive and aluminium substrate.

\section{$\underline{\text { References }}$}

1. D. Randall and S. Lee, The Polyurethanes Book, John Wiley \& Sons Ltd, 2002

2. R. G. Dillingham and C. Moriarty, J. Adhes. 2003; 79, 269.

3. M. M. Chehimi and J.F. Watts, J. Adhesion Sci. Technol. 1992; 6, 377.

4. J. Kim, J. Cho and Y-S Lim, J. Mater. Sci. 2005; 40, 2789.

5. R. A. De Souza, J. Zehnpfenning, M. Martin and J. Maier, Solid state Ionics 2005; 176, 1465.

6. J. F. Watts, A. Rattana and M.-L. Abel, Surf. Interf. Anal. 2004; 36, 1449.

7. M.-L. Abel, K. Shimizu, M. Holliman and J. F. Watts, Surf. Interf. Anal. 2009; 41, 265.

8. K. Shimizu, M.-L. Abel and J. F. Watts, J. Adhes. 2008; 84, 725.

9. S. Reichlmaier, J. S. Hammond, M. J. Hearn and D. Briggs, Surf. Interf. Anal. 1994; 21, 739.

10. M.-L. Abel, R. P. Digby, I. W. Fletcher and J. F. Watts, Surf. Interf. Anal. 2000; 29, 115.

11. G. Beamson and D. Briggs, High Resolustion XPS of Organic Polymers - The Scienta ESCA300 Database-, John Wiley and Sons, Chichester, 1992.

12. C. A. Melendres, S. Van Gils and H. Terryn, Electrochemi. Commun. 2001; 3737.

13. S. Van Giles, C. A. Melendres and H. Terryn, Surf. Interf. Anal. 2003; 35, 387.

14. M. R. Alexander, G. E. Thompson and G. Beamson, Surf. Interf. Anal. 2000; 29, 468.

15. M. R. Alexander, G. Beamson, C. J. Blomfield, G. Leggett and T. M. Duc, J. Electron. Spectrosc. Relat. Phenom. 2001; 131, 19.

16. F. Cordier and E. Ollivier, Surf. Interf. Anal. 1995; 23, 601.

17. Y. Deslandes, G. Pleizier, D. Alexander and P. Santerre, Polym. 1998; 39, 2361. 
18. J. F. Watts and J. Wolstenholme, An introduction to Surface Analysis by XPS and AES, John Wiley and Sons, Chichester, 2003.

19. I. Olefjord, H. J. Mathieu and P. Marcus, Surf. Interf. Anal. 1990; 15, 681.

20. Safety data sheet -SUPRASEC® 5025-, Huntsman PU, Everberg, 2008.

21. D. R. Lide, CRC Handbook of chemistry and physics ed. 81st, CRC Press, Cleveland, 2000.

22. P. J. Cumpson and M. P. Seah, Surf. Interf. Anal. 1997; 25, 430.

23. T. Gruke, "New Advanced in Polymeric MDI Variants" EUROCOAT 2002, Barcelona, Spain, 2002.

24. F. W. McLafferty and F. Tureček, Interpretation of Mass Spectra, University Science Book, California 1993.

25. M. J. Hearn, D. Briggs, S. C. Yoon and B. D. Ratner, Surf. Interf. Anal. 1987; 10, 384.

26. N. Nurdin, E. Weilandt, M. Textor, M. Taborelli, N. D. Spencer and P. Descouts, J. Appl. Polm. Sci. 1996; 61, 1939.

27. L. A. Pokrajac, M.Sc. Thesis, University of Toronto 1998.

28. H. Li, Y. Yan, B. Liu, W. Chen and S. Chen, Powder. Technol. 2009; 25, 2875.

29. Z. Li and K. Hirokawa, Appl. Surf. Sci. 2003; 220, 136. 
(a)

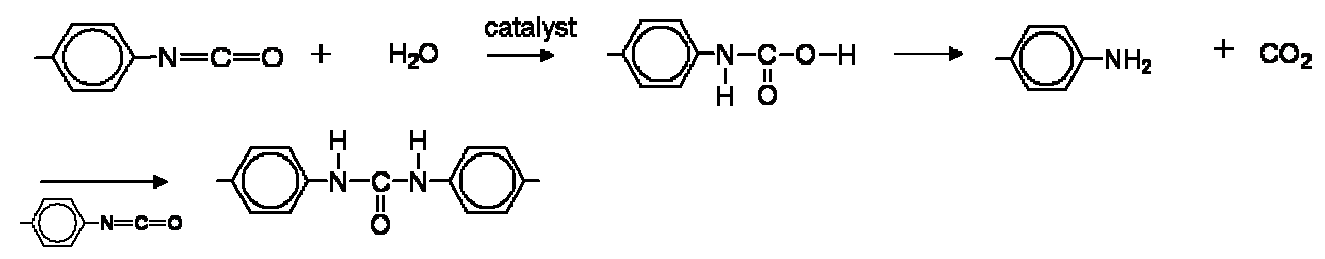

(b)

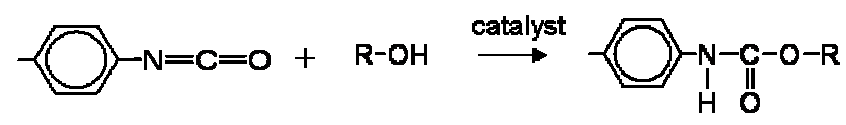

(c)

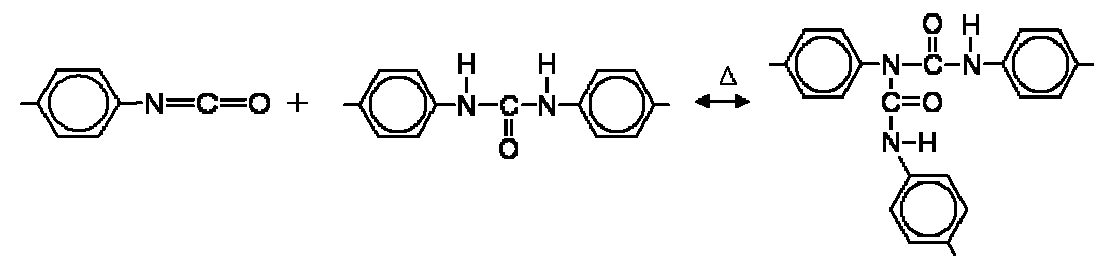

(d)

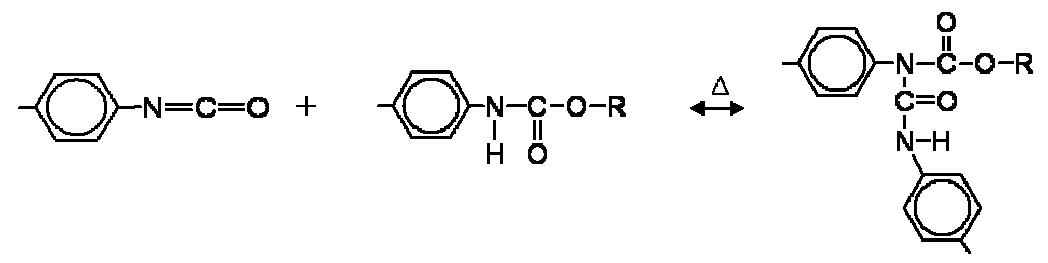

(e)

2

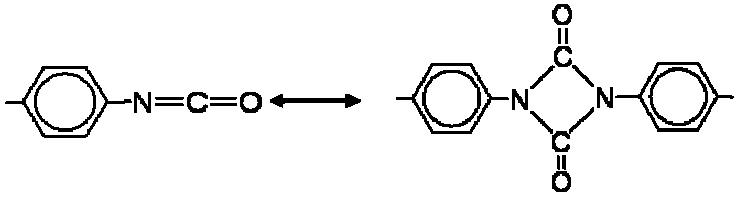

(f)

3
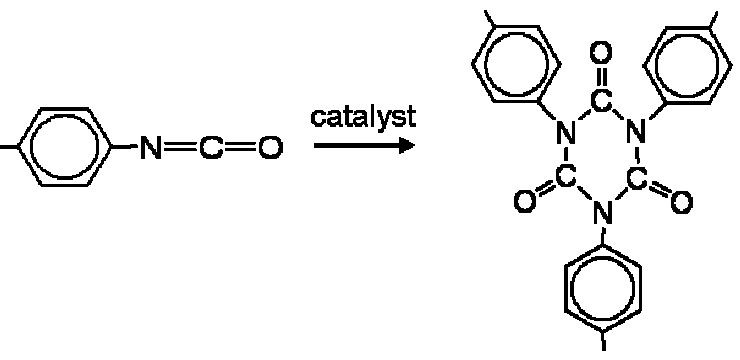

$(\mathrm{g})$

2

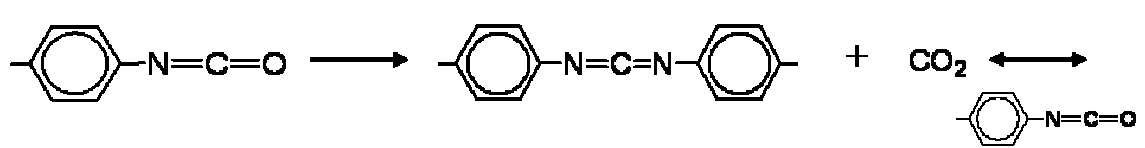<smiles></smiles>

Figure1: Synthesis of (a) urea (b) urethane, (c) biuret, (d) allophanate, (e) uretdione, (f) isocyanuate and $(\mathrm{g})$ carbodiimide and uretonimine formations 


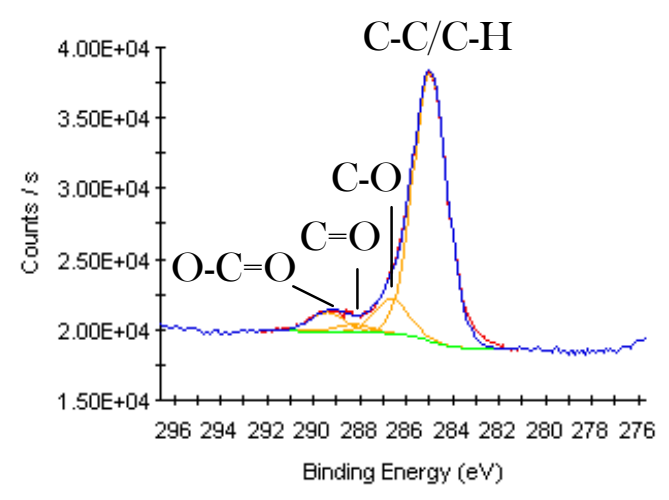

Figure 2: C1s peak fitting of degreased aluminium
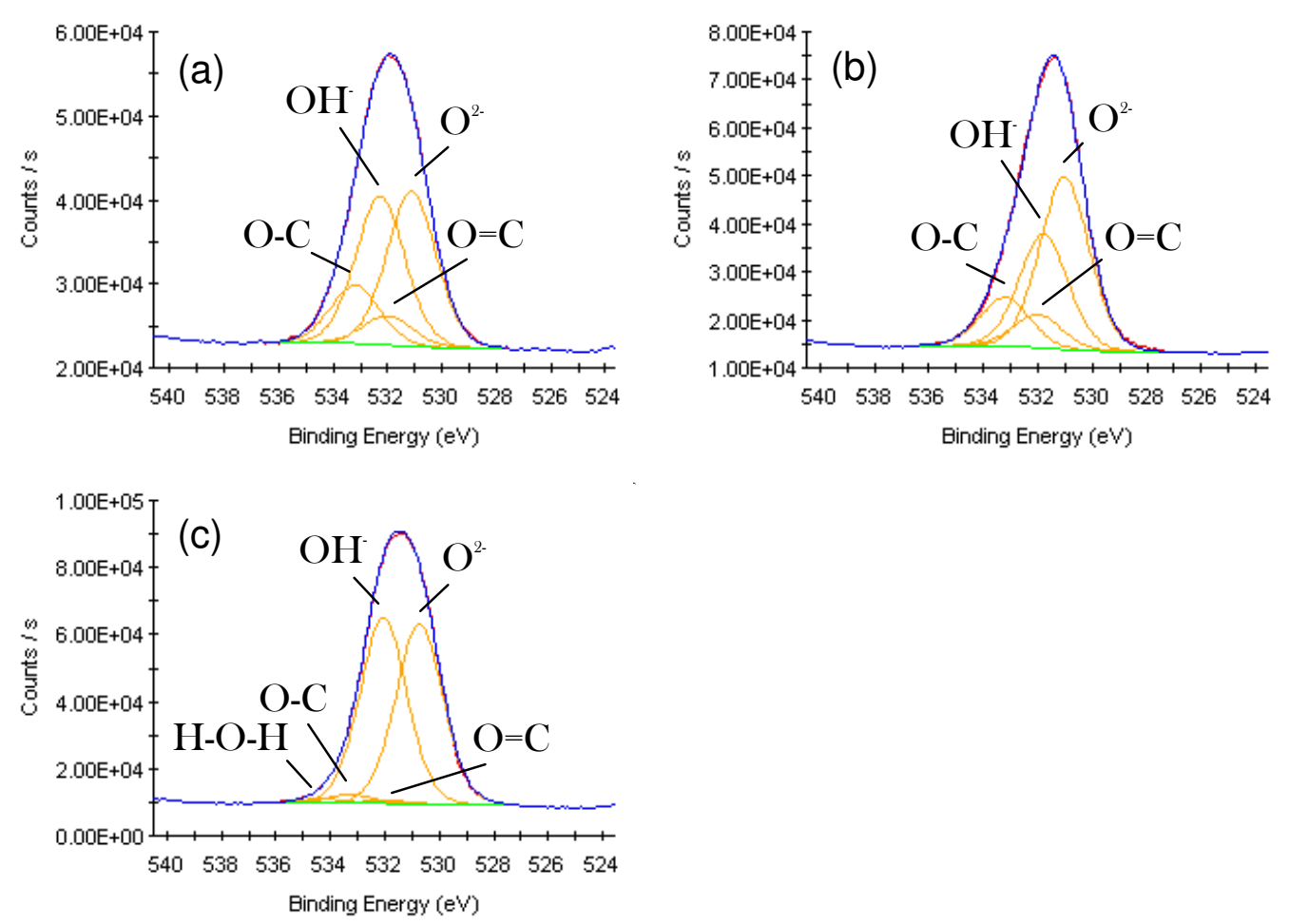

Figure 3: O1s peak fitting of (a) degreased, (b) oxidised and (c) hydrolysed aluminium 


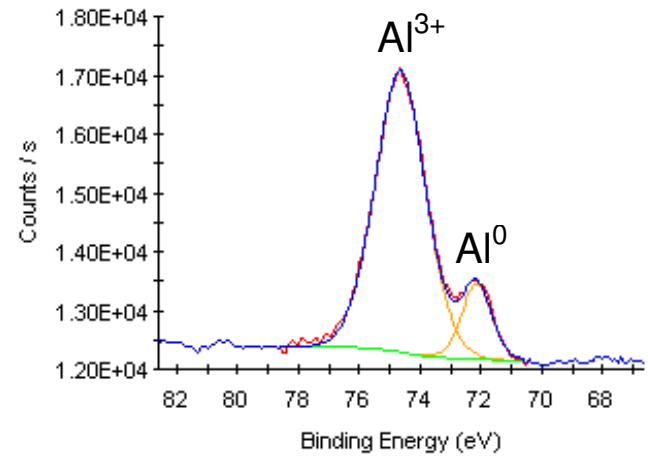

Figure 4: A12p peak fitting of degreased aluminium 

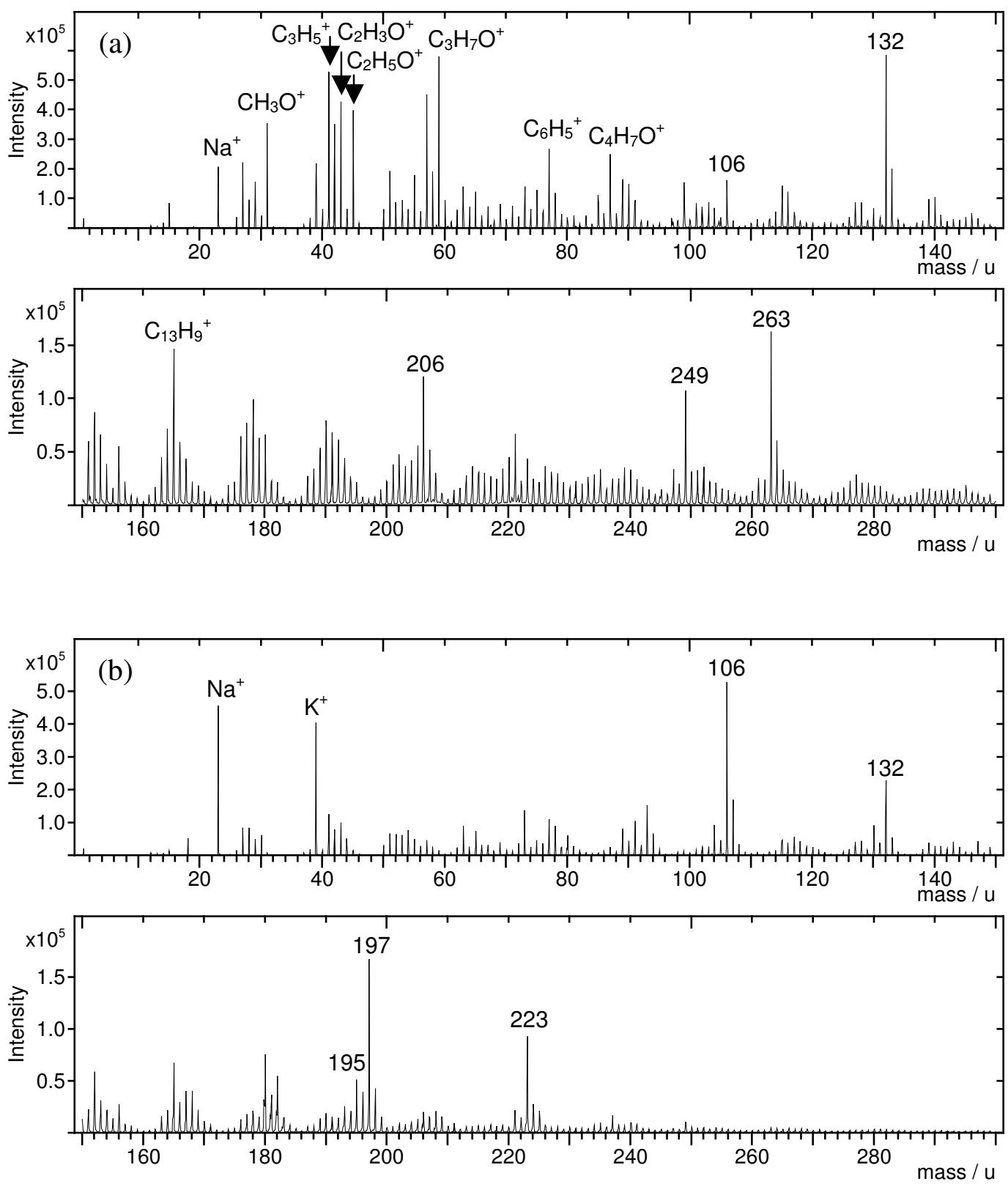

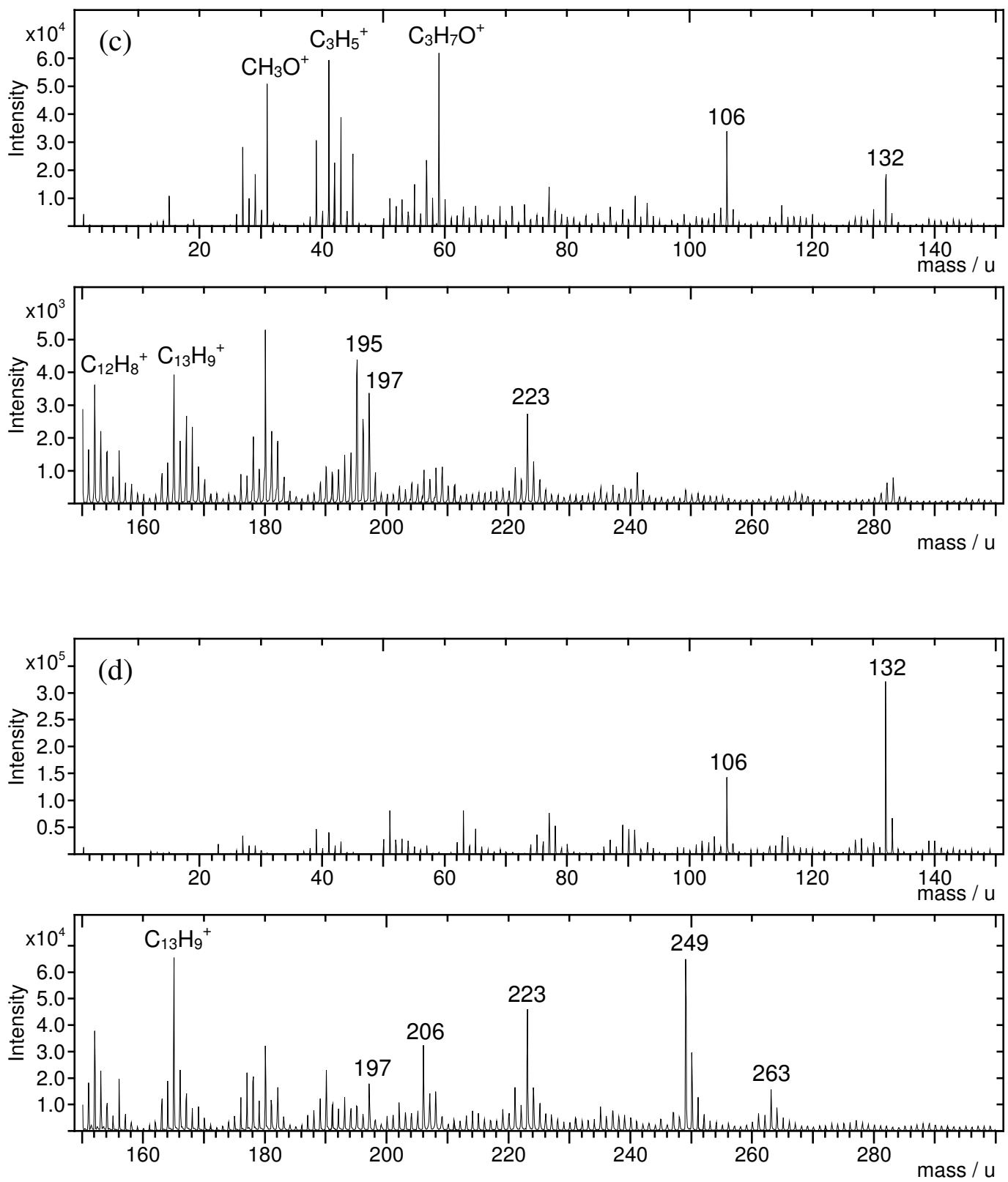

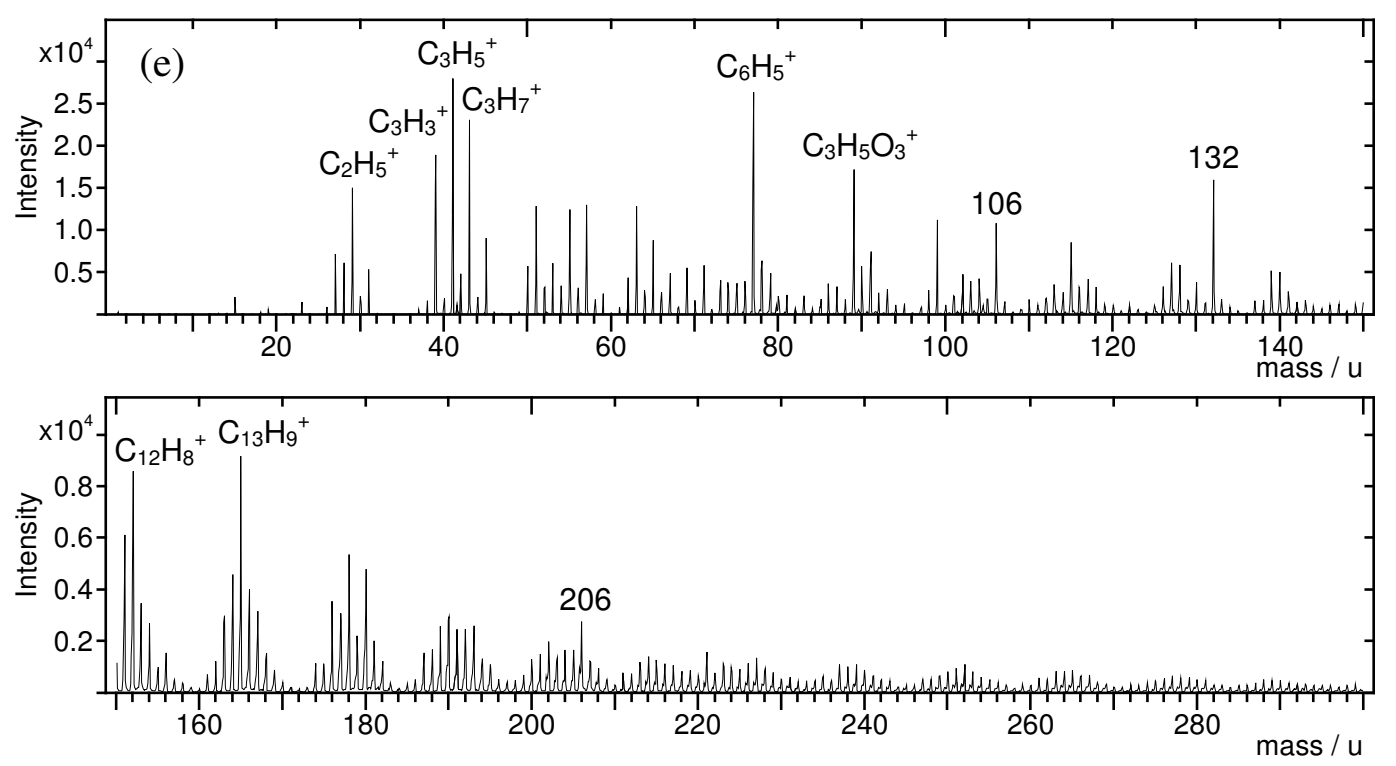

Figure 5: Positive ToF-SIMS spectra of reference samples: (a) PMDI, (b) high urea, (c) high urethane, (d) high uretdione and (e) high isocyanurate 

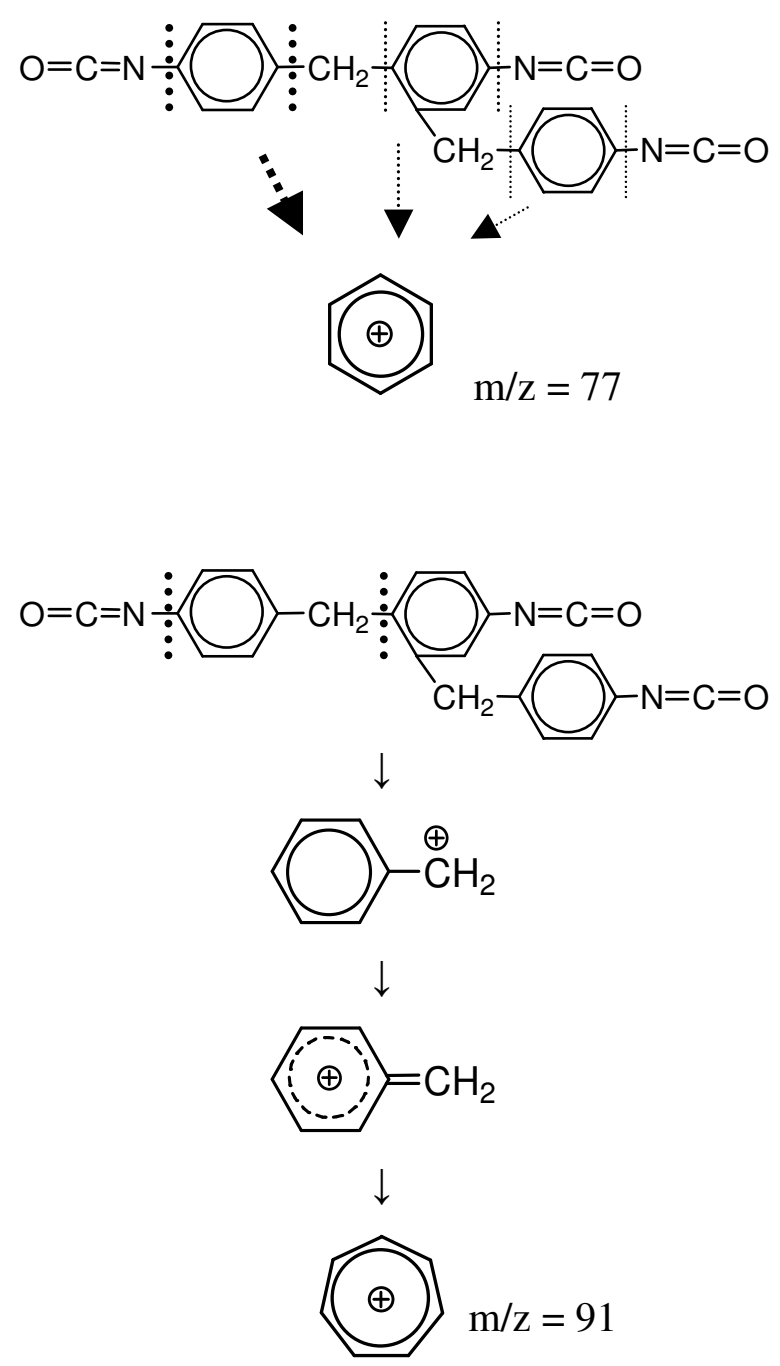
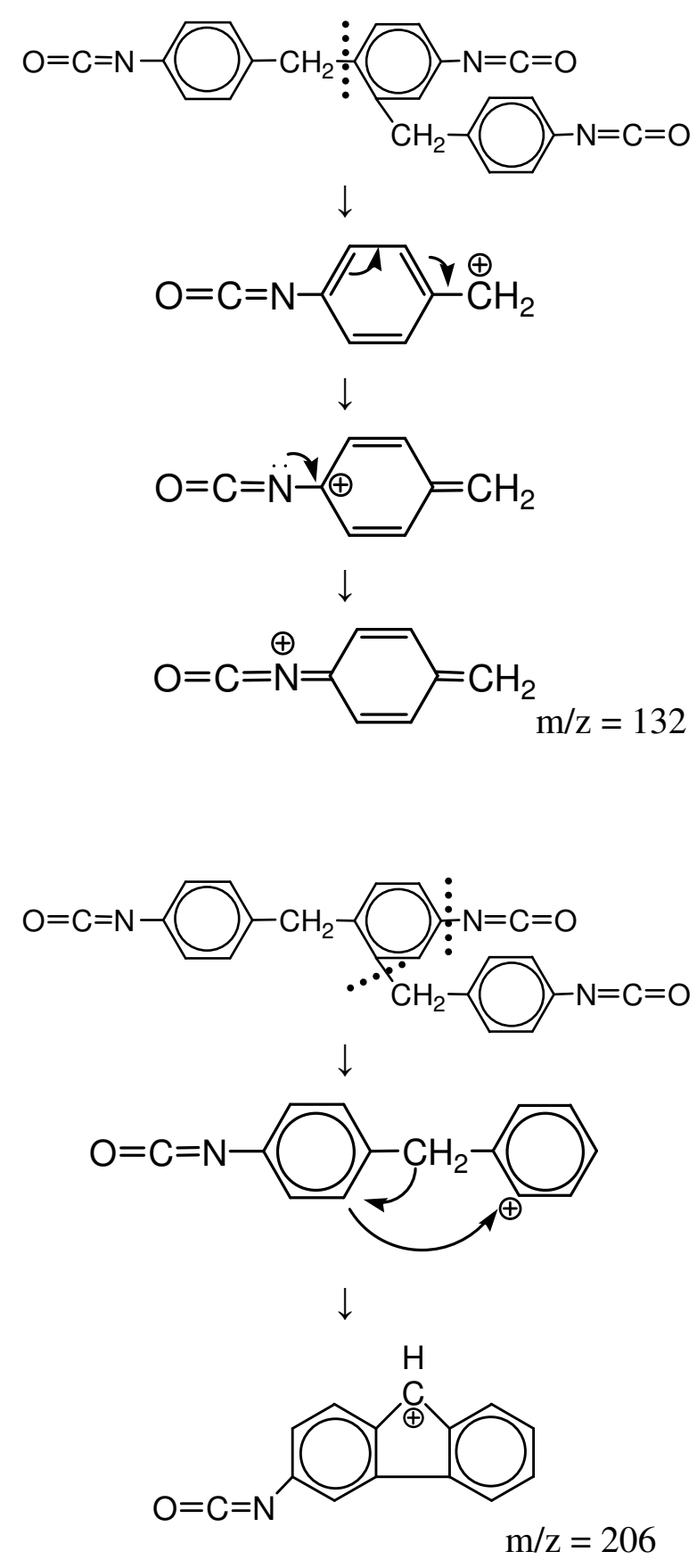

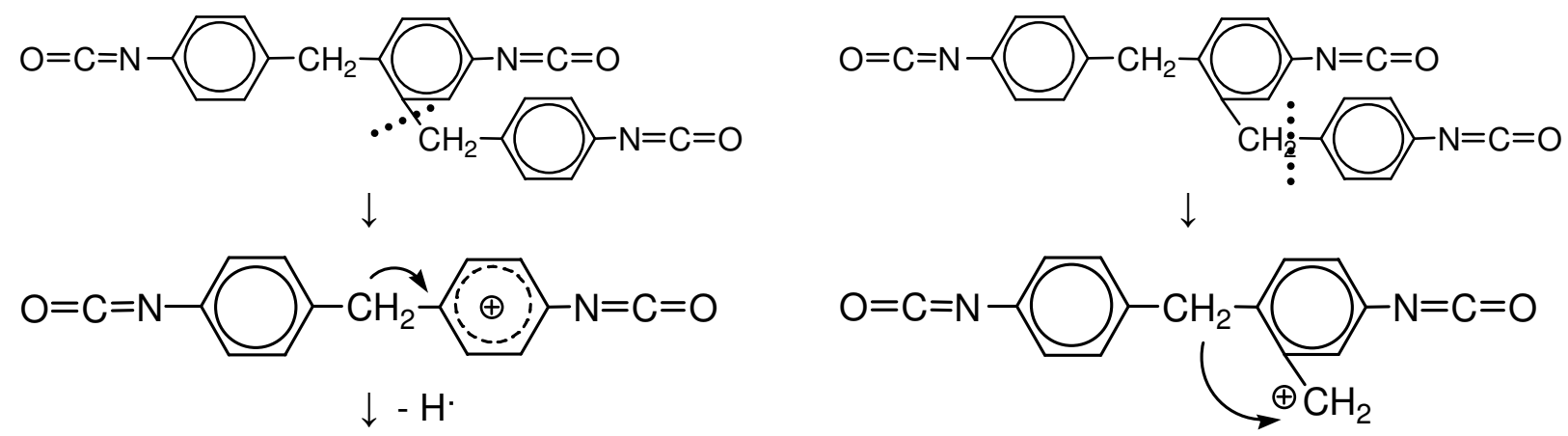

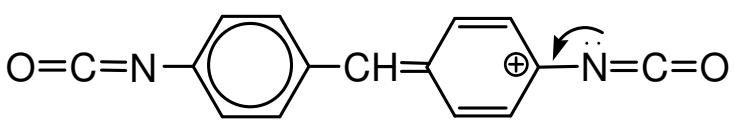

$\downarrow$

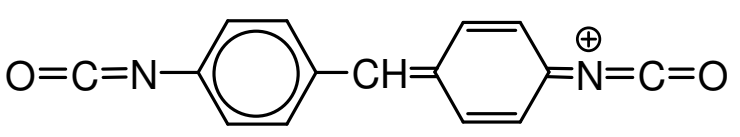

$\mathrm{m} / \mathrm{z}=249$
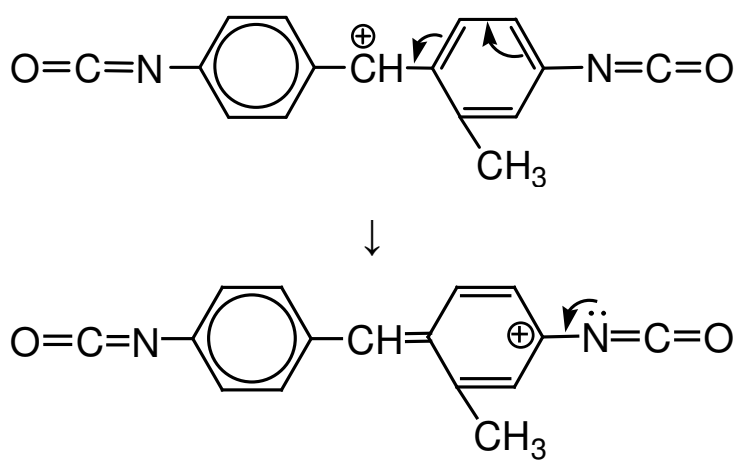

$\downarrow$

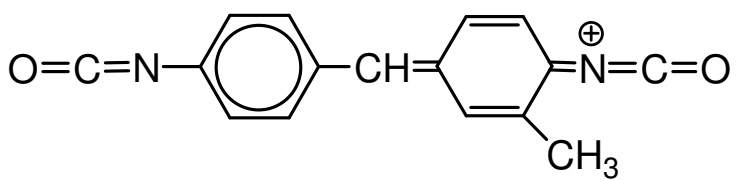

$\mathrm{m} / \mathrm{z}=263$

Figure 6: Fragmentation pattern of PMDI 

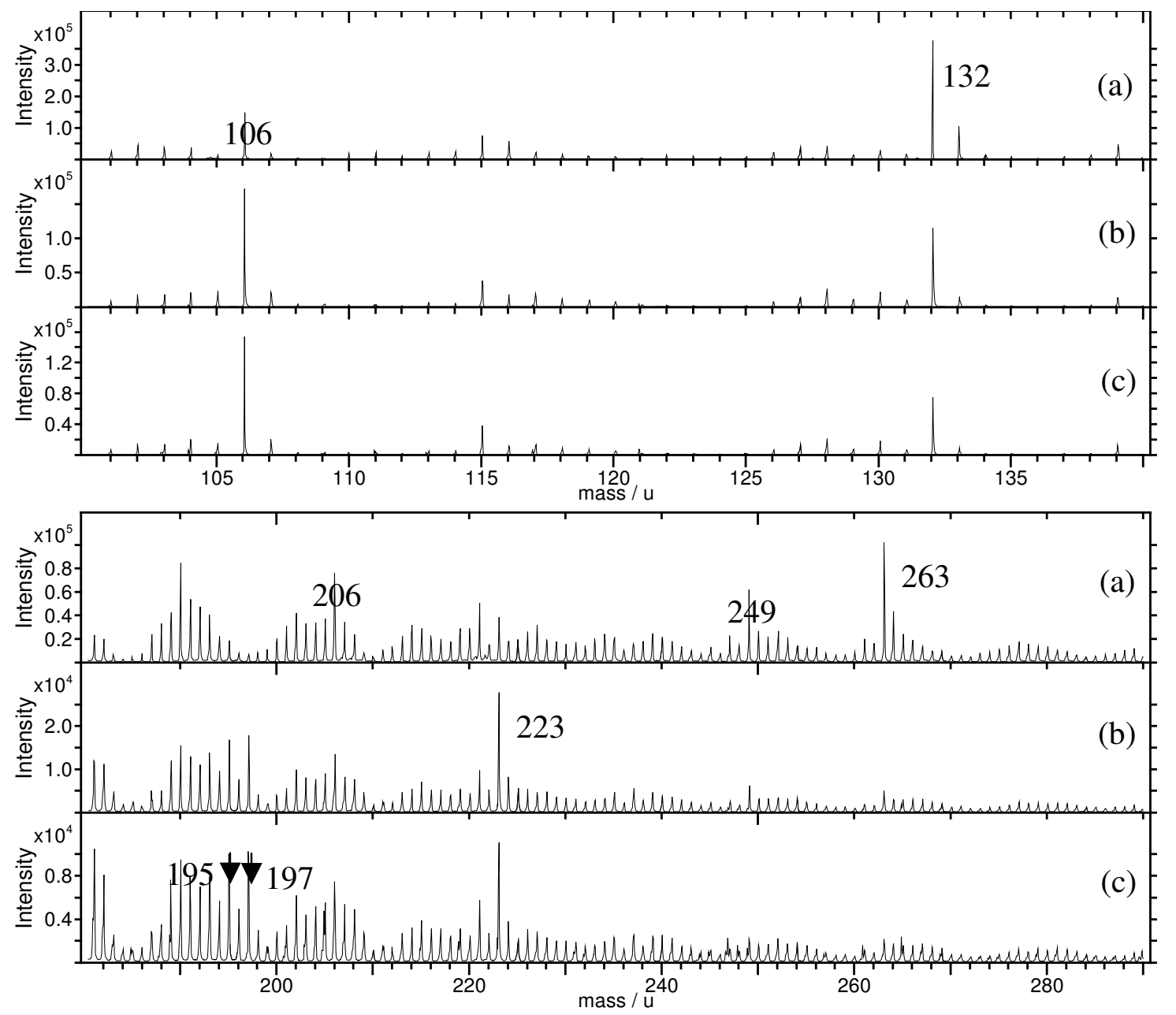

Figure 7: Positive ToF-SIMS spectra $(\mathrm{m} / \mathrm{z}=100-140$ and $180-290)$ of degreased aluminium treated with (a) 5 vol. \% PMDI (calculated film thickness: $7.3 \mathrm{~nm}$ ), (b) 0.25 vol. \% PMDI (calculated film thickness: $5.7 \mathrm{~nm}$ ) and (c) 0.05 vol. \% PMDI (calculated film thickness: $4.1 \mathrm{~nm}$ ) 


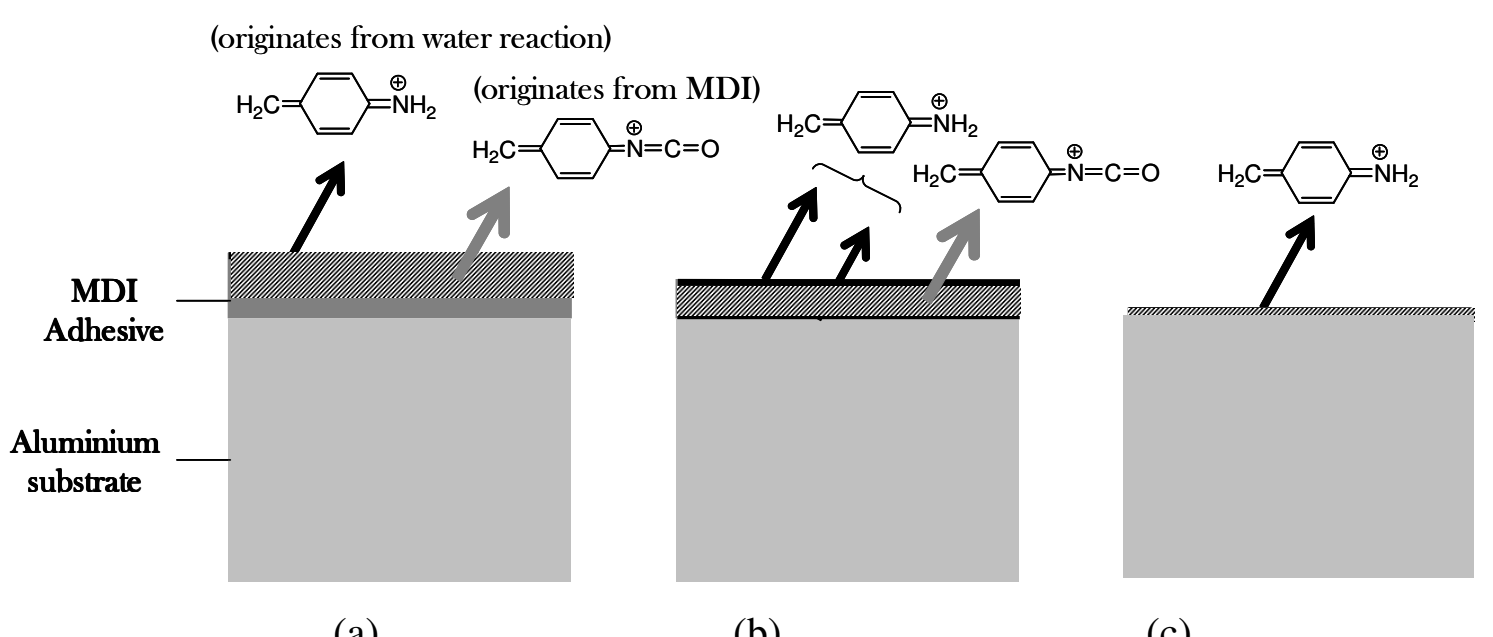

(a)

(b)

(c)

Figure 8: Schematic of depth information (a) thick $(>7.5 \mathrm{~nm})$, (b) intermediate $(4.1$ $7.4 \mathrm{~nm})$ and (c) thin $(<4.1 \mathrm{~nm})$ PMDI layer on aluminium samples

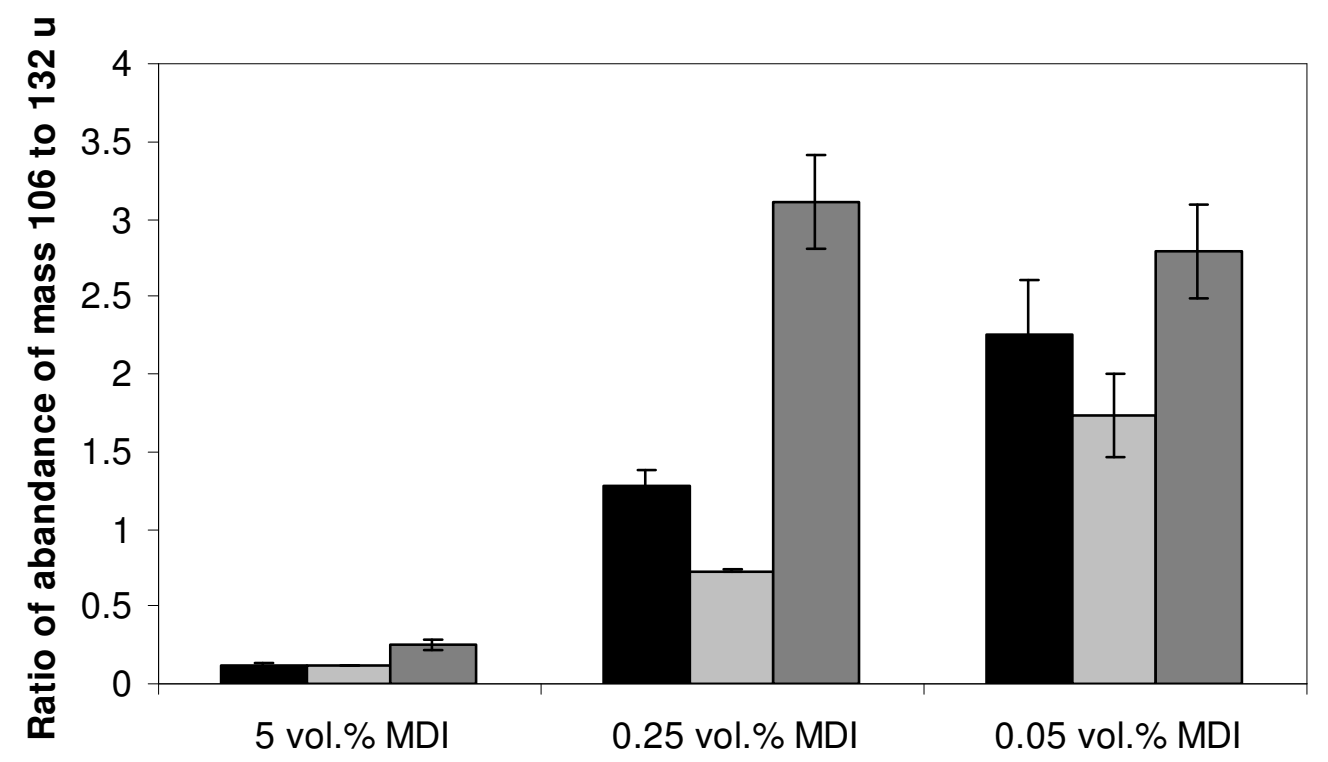

Figure 9: The ratio of the intensity of a fragment indicative of the reaction product with water $(\mathrm{m} / \mathrm{z}=106 \mathrm{u})$ to the intensity of isocyanate group $(\mathrm{m} / \mathrm{z}=132 \mathrm{u})$ of samples using different pretreated aluminium samples (left: degreased aluminium, middle: oxidised aluminium, right: hydrolysed aluminium) 


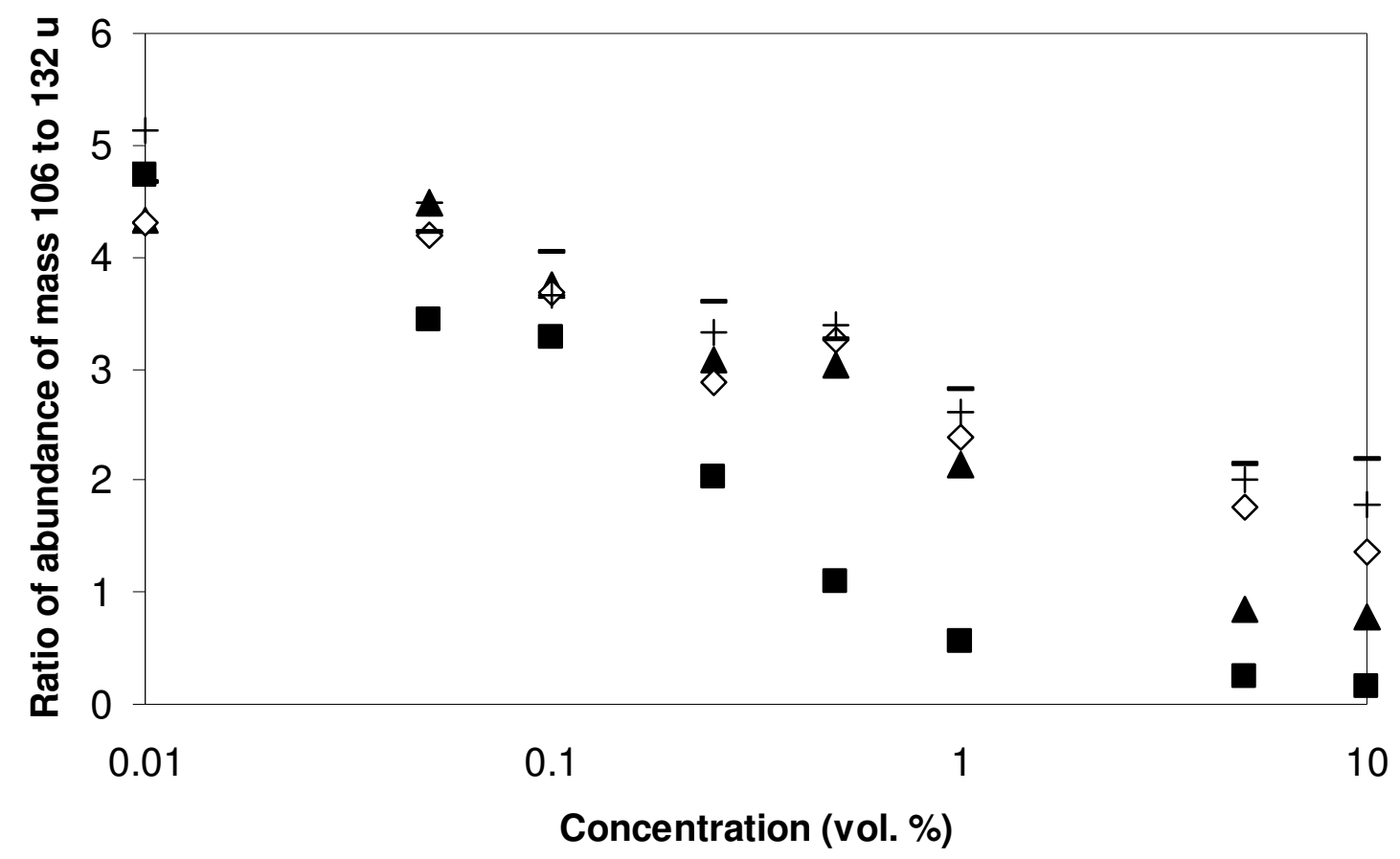

Figure 10: The ratio of the intensity of the fragment originating from the reaction product of isocyanate with water $(\mathrm{m} / \mathrm{z}=106 \mathrm{u})$ to that of the fragment originating from PMDI $(\mathrm{m} / \mathrm{z}=132 \mathrm{u})$ after exposure the MDI treated degreased aluminium samples to air for various periods ( $\mathbf{m}$ o day, $\boldsymbol{\Delta}: 2$ days, $\diamond: 3$ days, $+: 6$ days and $-: 14$ days) 

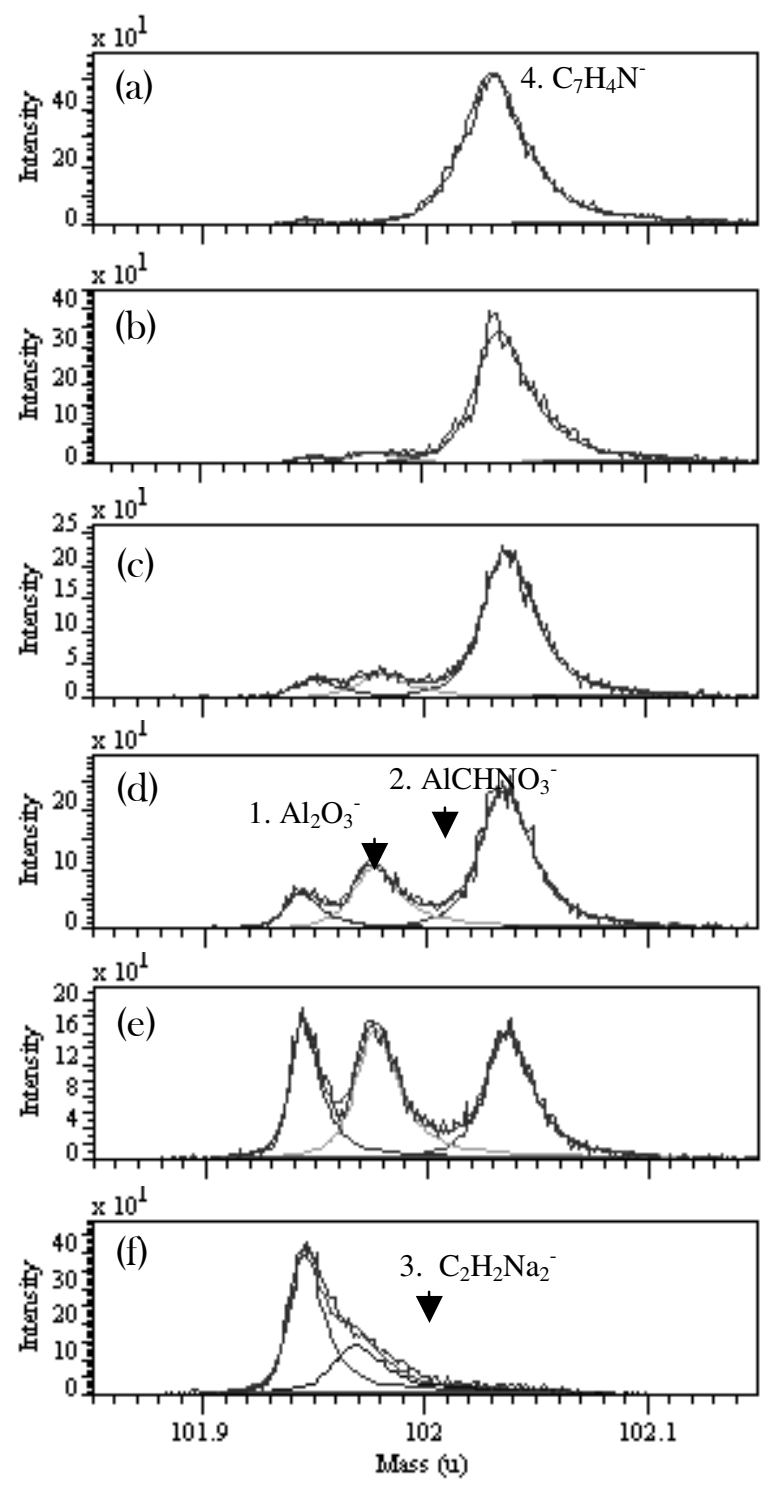

Figure 11: Spectra of nominal mass $\mathrm{m} / \mathrm{z}=102 \mathrm{u}$ at high mass resolution of degreased aluminium treated with (a) 5 vol. \%, (b) 0.5 vol. \%, (c) 0.25 vol. \%, (d) 0.1 vol. \%, (e) 0.05 vol. \% PMDI and (f) without PMDI

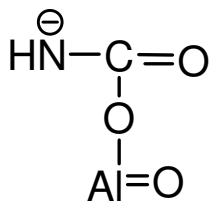

Figure 12: Proposed structure of $\mathrm{AlCHNO}_{3}{ }^{-}$fragment 
Table 1: Composition of reference samples

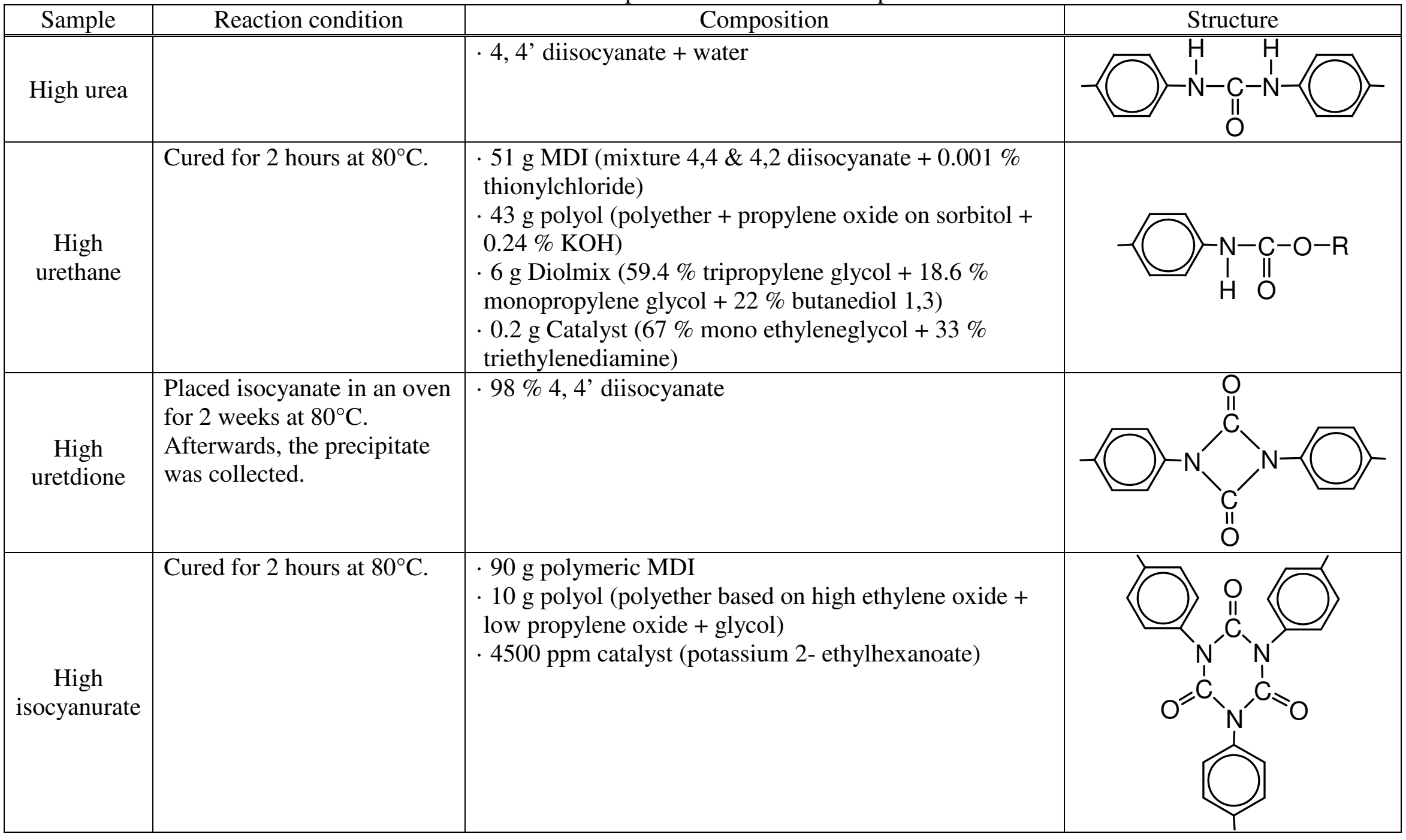


Table 2: XPS surface composition of three different pretreated aluminium substrates

\begin{tabular}{ccccc}
\hline \multirow{2}{*}{ Sample } & \multicolumn{4}{c}{ Surface concentration (at. \%) } \\
\cline { 2 - 5 } & $\mathrm{Al}$ & $\mathrm{O}$ & $\mathrm{C}$ & $\mathrm{N}$ \\
\hline Degreased Al & 14.1 & 42.9 & 42.4 & 0.5 \\
Oxidised Al & 22.3 & 55.9 & 21.8 & - \\
Hydrolysed Al & 20.1 & 71.1 & 8.8 & - \\
\hline
\end{tabular}

Table 3: Carbon functionalities with their binding energies of variable aluminium substrates

\begin{tabular}{ccccc}
\hline \multirow{2}{*}{ Sample } & \multicolumn{4}{c}{$\begin{array}{c}\text { Surface concentration of C1s peak fitting (at. \%) } \\
\end{array}$} \\
\cline { 2 - 5 } & $\mathrm{C}-\mathrm{C} / \mathrm{C}-\mathrm{H}$ & $\mathrm{C}-\mathrm{O} / \mathrm{C}-\mathrm{OH}$ & $\mathrm{C}=\mathrm{O}$ & $\mathrm{O}-\mathrm{C}=\mathrm{O}$ \\
\hline \multirow{2}{*}{ Degreased Al } & 31.6 & 6.3 & 1.3 & 2.6 \\
& $(285.0)$ & $(286.4)$ & $(287.9)$ & $(289.5)$ \\
Oxidised Al & 14.1 & 3.5 & 1.5 & 2.6 \\
& $(285.0)$ & $(286.3)$ & $(287.8)$ & $(289.4)$ \\
Hydrolysed Al & 7.2 & 1.0 & - & 0.5 \\
& $(285.0)$ & $(286.4)$ & - & $(288.8)$ \\
\hline
\end{tabular}

Table 4: Oxygen functionalities with their binding energies of variable aluminium substrates

\begin{tabular}{ccccccc}
\hline \multirow{2}{*}{ Sample } & \multicolumn{5}{c}{$\begin{array}{c}\text { Surface concentration of O1s peak fitting (at. \%) } \\
\text { (The binding energies of peak fitting (eV)) }\end{array}$} \\
\cline { 2 - 7 } & $\mathrm{Al}-\mathrm{O}$ & $\mathrm{Al}-\mathrm{OH}$ & $\mathrm{H}-\mathrm{O}-\mathrm{H}$ & $\mathrm{C}=\mathrm{O}$ & $\mathrm{C}-\mathrm{O}$ & $\mathrm{Al}-\mathrm{OH} / \mathrm{Al}-\mathrm{O}$ \\
\hline \multirow{2}{*}{ Degreased Al } & 17.1 & 16.5 & - & 3.2 & 6.4 & 0.96 \\
& $(531.2)$ & $(532.3)$ & - & $(532.0)$ & $(533.2)$ & \\
\multirow{2}{*}{ Oxidised Al } & 26.3 & 17.4 & - & 5.0 & 7.5 & 0.66 \\
& $(531.2)$ & $(531.9)$ & - & $(532.1)$ & $(533.3)$ & \\
\multirow{2}{*}{ Hydrolysed Al } & 33.9 & 35.0 & 0.5 & 0.6 & 1.6 & 1.03 \\
& $(530.8)$ & $(532.1)$ & $(534.4)$ & $(532.1)$ & $(533.4)$ & \\
\hline
\end{tabular}

Table 5: aluminium functionalities with their binding energies of variable aluminium substrates

\begin{tabular}{cccc}
\hline \multirow{2}{*}{ Sample } & \multicolumn{3}{c}{$\begin{array}{c}\text { Surface concentration of Al2p peak fitting (at. \%) } \\
(\text { The binding energies of peak fitting (eV)) }\end{array}$} \\
\cline { 2 - 4 } & $\mathrm{Al}^{0}$ & $\mathrm{Al}^{3}$ & $\mathrm{Al}^{3} /\left(\mathrm{Al}^{0}+\mathrm{Al}^{3}\right)$ \\
\hline \multirow{2}{*}{ Degreased Al } & 2.0 & 12.1 & 0.86 \\
& $(72.2)$ & $(74.7)$ & \\
Oxidised Al & 4.1 & 18.0 & 0.81 \\
& $(72.0)$ & $(74.7)$ & \\
Hydrolysed Al & - & 20.1 & 1.00 \\
& - & $(74.2)$ & \\
\hline
\end{tabular}


Table 6: XPS surface composition of variable concentration PMDI treated aluminium

\begin{tabular}{ccccc}
\hline pMDI concentration & \multicolumn{4}{c}{ Surface concentration (at. \%) } \\
\cline { 2 - 5 } (vol. \%) & $\mathrm{C}$ & $\mathrm{N}$ & $\mathrm{O}$ & $\mathrm{Al}$ \\
\hline Degreased aluminium & 42.4 & 0.5 & 42.9 & 14.1 \\
0.01 & 30.3 & 1.3 & 50.3 & 18.1 \\
0.05 & 47.3 & 3.9 & 36.9 & 11.9 \\
0.1 & 51.7 & 5.6 & 31.8 & 10.9 \\
0.25 & 64.3 & 9.4 & 20.5 & 5.8 \\
0.5 & 65.4 & 8.9 & 20.2 & 5.6 \\
1 & 68.0 & 10.2 & 17.4 & 4.4 \\
5 & 72.1 & 11.2 & 14.3 & 2.5 \\
10 & 72.8 & 11.3 & 13.6 & 2.3 \\
\hline
\end{tabular}

Table 7: Carbon functionalities with their binding energies of variable concentration PMDI treated aluminium

\begin{tabular}{|c|c|c|c|c|c|}
\hline \multirow{3}{*}{$\begin{array}{c}\text { PMDI } \\
\text { concentration } \\
(\text { vol. } \%)\end{array}$} & \multicolumn{5}{|c|}{$\begin{array}{l}\text { Surface concentration of C1s peak fitting (at. \%) } \\
\text { (The binding energies of peak fitting }(\mathrm{eV}))\end{array}$} \\
\hline & $1^{\text {st }}$ peak & $2^{\text {nd }}$ peak & $3^{\text {rd }}$ peak & $4^{\text {th }}$ peak & $5^{\text {th }}$ peak \\
\hline & $\mathrm{C}-\mathrm{C} / \mathrm{C}-\mathrm{H}$ & $\begin{array}{c}\mathrm{C}-\mathrm{N} / \\
\mathrm{C}-\mathrm{O} / \mathrm{C}-\mathrm{OH}\end{array}$ & $\mathrm{C}=\mathrm{O}$ & $\begin{array}{c}\mathrm{N}=\mathrm{C}=\mathrm{O} / \\
\mathrm{N}-\mathrm{CN}=\mathrm{O} / \\
\mathrm{N}-\mathrm{COH}=\mathrm{O} / \\
\mathrm{O}-\mathrm{C}=\mathrm{O}\end{array}$ & $\begin{array}{l}\text { Shake-up } \\
\text { satellite }\end{array}$ \\
\hline \multirow{2}{*}{ Degreased Al } & 37.8 & 4.9 & 1.1 & 2.7 & - \\
\hline & (285.0) & (286.7) & $(288.3)$ & (289.4) & - \\
\hline \multirow{2}{*}{0.01} & 20.9 & 5.1 & 1.9 & 2.5 & - \\
\hline & (285.0) & $(286.1)$ & $(287.8)$ & (289.5) & - \\
\hline \multirow{2}{*}{0.05} & 37.7 & 5.8 & - & 3.9 & - \\
\hline & (285.0) & (285.8) & - & $(289.1)$ & - \\
\hline \multirow{2}{*}{0.1} & $* 38.4$ & 9.2 & - & 4.2 & \\
\hline & (285.0) & (286.3) & - & $(289.2)$ & (291.4) \\
\hline \multirow{2}{*}{0.25} & $* 48.9$ & 10.5 & - & 4.9 & - \\
\hline & (285.0) & $(286.2)$ & - & (289.4) & (291.8) \\
\hline \multirow[b]{2}{*}{0.5} & $* 49.6$ & 11.0 & - & 4.9 & - \\
\hline & (285.0) & $(286.2)$ & - & $(289.3)$ & (291.7) \\
\hline \multirow{2}{*}{1} & $* 51.2$ & 11.7 & - & 5.1 & - \\
\hline & (285.0) & $(286.2)$ & - & (289.4) & (291.8) \\
\hline \multirow{2}{*}{5} & $* 54.1$ & 12.4 & - & 5.6 & - \\
\hline & (285.0) & $(286.2)$ & - & (289.4) & (291.9) \\
\hline \multirow{2}{*}{10} & $* 54.1$ & 13.2 & - & 5.4 & - \\
\hline & (285.0) & (285.9) & - & (289.4) & (291.8) \\
\hline
\end{tabular}

*: Including shake-up satellite component 
Table 8: Thickness of carbonaceous layer of PMDI treated aluminium samples

\begin{tabular}{cccc}
\hline PMDI & \multicolumn{3}{c}{ Thickness (nm) } \\
\cline { 2 - 4 } $\begin{array}{c}\text { concentration } \\
(\text { vol. \%) }\end{array}$ & Degreased Al & Oxidised Al & Hydrolysed Al \\
\hline 0.01 & 2.8 & & \\
0.05 & 4.1 & 4.0 & 1.9 \\
0.1 & 4.4 & 5.2 & 2.7 \\
0.25 & 5.7 & & \\
0.5 & 5.8 & 10.5 & - \\
1 & 6.3 & & \\
5 & 7.3 & & \\
10 & 7.5 & & \\
\hline
\end{tabular}

Table 9: Possible structures of positive ion fragments from the PMDI and related reaction products

\begin{tabular}{|c|c|c|}
\hline Mass & Formula & Structure \\
\hline 77 & $\mathrm{C}_{6} \mathrm{H}_{5}{ }^{+}$ & \\
\hline 91 & $\mathrm{C}_{7} \mathrm{H}_{7}^{+}$ & \\
\hline 106 & $\mathrm{C}_{7} \mathrm{H}_{8} \mathrm{~N}^{+}$ & . \\
\hline 132 & $\mathrm{C}_{8} \mathrm{H}_{6} \mathrm{NO}^{+}$ & . \\
\hline 195 & $\mathrm{C}_{13} \mathrm{H}_{11} \mathrm{~N}_{2}^{+}$ & \\
\hline 197 & $\mathrm{C}_{13} \mathrm{H}_{13} \mathrm{~N}_{2}^{+}$ & \\
\hline 206 & $\mathrm{C}_{14} \mathrm{H}_{8} \mathrm{NO}^{+}$ & \\
\hline 223 & $\mathrm{C}_{14} \mathrm{H}_{11} \mathrm{~N}_{2} \mathrm{O}^{+}$ & \\
\hline 249 & $\mathrm{C}_{15} \mathrm{H}_{9} \mathrm{~N}_{2} \mathrm{O}_{2}^{+}$ & $\mathrm{O}=\mathrm{C}=\mathrm{N}$ \\
\hline 263 & $\mathrm{C}_{16} \mathrm{H}_{11} \mathrm{~N}_{2} \mathrm{O}_{2}^{+}$ & $=\stackrel{\oplus}{\mathrm{N}}=\mathrm{C}=\mathrm{C}$ \\
\hline
\end{tabular}


Table 10: The main characteristic fragments observed from the reference samples

\begin{tabular}{|c|c|c|c|c|c|c|c|c|c|c|}
\hline \multirow{2}{*}{ Sample } & \multicolumn{10}{|c|}{ Mass (u) } \\
\cline { 2 - 13 } & 77 & 91 & 106 & 132 & 195 & 197 & 206 & 223 & 249 & 263 \\
\hline \hline MDI & $\checkmark$ & $\checkmark$ & $\checkmark$ & $\checkmark$ & - & - & $\checkmark$ & - & $\checkmark$ & $\checkmark$ \\
\hline High urea & $\checkmark$ & $\checkmark$ & $\checkmark$ & $\checkmark$ & $\checkmark$ & $\checkmark$ & - & $\checkmark$ & - & - \\
\hline High urethane & $\checkmark$ & $\checkmark$ & $\checkmark$ & $\checkmark$ & $\checkmark$ & $\checkmark$ & - & $\checkmark$ & - & - \\
\hline High uretdione & $\checkmark$ & $\checkmark$ & $\checkmark$ & $\checkmark$ & - & $\checkmark$ & $\checkmark$ & $\checkmark$ & $\checkmark$ & $\checkmark$ \\
\hline High isocyanurate & $\checkmark$ & $\checkmark$ & $\checkmark$ & $\checkmark$ & - & - & $\checkmark$ & - & - & - \\
\hline
\end{tabular}

Table 11: Fragment obtained at nominal mass 102 and their respective assignment

\begin{tabular}{|c|c|c|c|c|}
\hline Peak no. & Experimental mass $(\mathrm{u})$ & Exact mass $(\mathrm{u})$ & $|\Delta|(\mathrm{ppm})$ & Formula \\
\hline \hline 1 & $101.9434-101.9506$ & 101.9478 & $6.9-43.2$ & $\mathrm{Al}_{2} \mathrm{O}_{3}{ }^{-}$ \\
\hline 2 & $101.9758-101.9793$ & 101.9772 & $3.9-20.6$ & $\mathrm{AlCHNO}_{3}{ }^{-}$ \\
\hline 3 & 101.9683 & 101.9694 & 10.8 & $\mathrm{C}_{2} \mathrm{O}_{2} \mathrm{Na}_{2}{ }^{-}$ \\
\hline 4 & $102.0289-102.0364$ & 102.0344 & $2.9-53.9$ & $\mathrm{C}_{7} \mathrm{H}_{4} \mathrm{~N}^{-}$ \\
\hline
\end{tabular}

